\title{
DOGMÁTICA DE LA ORGANIZACIÓN DE PODERES EN LA LEY FUNDAMENTAL DE BONN
}

\author{
CHRISTOPH MÖLLERS \\ Catedrático de Derecho público, Derecho comparado \\ y Teoría de la Constitución Universidad de Göttingen
}

\section{SUMARIO}

I. Introducción.

II. Estado actual de la doctrina y de la jurisprudencia.

III. Un análisis sistemático de la organización de poderes en la Ley Fundamental.

IV. Los tres Poderes y sus interrelaciones jurídicas.

V. La organización de poderes en las relaciones jurídicas verticales.

VI. La organización de poderes en la supremacía de la Constitución.

VII. Sobre el método de interpretación del artículo 20.2.2 GG.

VIII. Conclusión.

\section{INTRODUCCIÓN}

El artículo 20.2.2 GG, el principio de la organización de poderes ${ }^{1}$, es una norma que ha sido dogmáticamente descuidada. Aunque ha desempeñado un papel importante (también en comparación con otras de las decisiones fundamentales contenidas en el artículo 20 GG) en la jurisprudencia del Tribunal Constitucional Federal desde sus inicios ${ }^{2}$, los estudios monográficos han sido

1 Sobre la terminología, infra III.,1.

2 Sobre la jurisprudencia más antigua, véanse los estudios generales de B. SinEmus, Der Grundsatz der Gewaltenteilung in der Rechtsprechung des Bundesverfassungsgerichts, 1985, págs. 100 ss.; y D. Rauschming, "Das parlamentarische Regierungssystem des Grundgesetzes in der Rechtsprechung des Bundesverfassungsgerichts", en: Festschrift 50 Jahre BVerfG, vol. 2, 1976, pág. 214 (255 ss.). Sobre la jurisprudencia más reciente véanse las próximas notas. 
escasos $^{3}$ y los artículos relevantes también son pocos ${ }^{4}$. No pocos trabajos cuestionan tanto la relevancia práctica de la norma como la posibilidad de su análisis dogmático 5 . Frente a esto, el presente trabajo intentará desarrollar una fundamentación dogmática del artículo 20.2.2 GG que conciba la organización de poderes como la manifestación organizativa del principio democrático y del Estado de Derecho (III.). De esta interpretación se derivan implicaciones sistemáticas para la definición de los tres Poderes y sus relaciones mutuas (IV.), para las relaciones constitucionales dentro del Estado federal y hacia el exterior (V.) y para la posición jurídico-organizativa del Tribunal Constitucional Federal (VI.), lo cual permitirá finalmente una reflexión acerca del tratamiento metodológico del artículo 20.2.2 GG (VII). Todo lo anterior hace preciso en primer lugar un breve examen del estado actual de la doctrina y de la jurisprudencia (II.).

\section{ESTADO ACTUAL DE LA DOCTRINA Y DE LA JURISPRUDENCIA}

\section{RELEVANCIA SUMARIA O INTEGRAL}

¿Tiene el principio de la organización de poderes de la Ley Fundamental un contenido normativo propio o queda diluido en sus componentes individuales? A diferencia de lo que ocurre con los principios democrático y del Estado de Derecho ${ }^{6}$, esta cuestión no se suele abordar explícitamente en el caso de la organización de poderes. Está claro, en cualquier caso, que la discusión científica se mueve a lo largo de la norma en dos tendencias contrapuestas: por un lado, no hay apenas problemas derivados de la organización de poderes para cuya solución no resulten apropiadas también otras normas más específicas de la Ley Fundamental ${ }^{7}$. Las interrelaciones organizativas y procedimentales cuestionadas están, en la mayoría de los casos, reguladas en la Ley Fundamental de manera expresa, lo cual podría sugerir limitar la organización de poderes a las disposiciones concretas relevantes de la Ley Fundamental y a entenderla de forma sumaria, esto es, como el epítome de estas

3 Se pueden mencionar: N. ACHTERBERg, Probleme der Funktionenordnung, 1970; G. Zimmer, Kompetenz - Funktion - Legitimation, 1979; H.D. JARASs, Politik und Bürokratie als Elemente der Gewaltenteilung, 1975, págs. 4 ss. Las más cercanas a la aproximación que se hace en este análisis son las reflexiones de W. Heun, Staatshaushalt und Staatsleitung, 1989, págs. 85 ss.

4 Referencias de aquí en adelante.

5 T. Kunt, Kernbereich der Exekutive, 1993, págs. 130 ss., con referencias adicionales; F. OssenbÜHL, "Aktuelle Probleme der Gewaltenteilung", DÖV 1980, pág. 545 (545); W. LeISNER, "Die quantitative Gewaltenteilung", DÖV 1969, pág. 405 (407 ss.); R. STETTNER, "Not und Chance der grundgesetzlichen Gewaltenteilung”, JöR n. F. 35 (1986), pág. 57 (60 ss.).

6 Sobre la discusión al respecto: E. SChMidT-Armann, "Der Rechtsstaat", en: J. Isensez/P KirchHof (eds.): Handbuch des Staatsrechts, vol. II, 3. ed. 2004, \26, marginal 7; M. JESTAEDT, Demokratieprinzip und Kondominialverwaltung, 1993, págs. 149 y siguiente.

7 Sobre el problema metodológico: KuHL, Kernbereich (nota 5), págs. 100 ss.; cauteloso por ello sobre el contenido normativo: OssenbüHL, Probleme (nota 5), pág. 545 (545). 
normas ${ }^{8}$. Por otro lado, un vistazo superficial a la jurisprudencia del Tribunal Constitucional Federal pone ya de manifiesto que el recurso a normas concretas no basta para decidir este tipo de cuestiones constitucionales polémicas. No es casualidad que la organización de poderes desempeñe en la jurisprudencia el papel de norma de fondo 9 que se activa en una sorprendente variedad de supuestos ${ }^{10}$. Aquí se revela la necesidad práctica de una comprensión sistemática e integral de la organización de poderes que parece necesaria, más allá de las preguntas teóricas imaginables ${ }^{11}$, para comprender la jurisprudencia ${ }^{12}$. La reducción del principio de la organización de poderes a normas concretas de la Ley Fundamental ni satisface la necesidad dogmática de construcción de un sistema ni ayuda a descifrar la praxis de la jurisprudencia constitucional.

\section{Deducción a partir de las ideas de Democracia Y DE ESTADO DE DERECHO}

Si se busca en la bibliografía científica básica el principio de la organización de poderes ${ }^{13}$ se le encuentra ubicado bajo la rúbrica del principio del Es-

8 En este sentido: Zimmer, Funktion (nota 3), págs. 324 ss.; H.D. Horn, "Gewaltenteilige Demokratie, demokratische Gewaltenteilung", AöR 127 (2002), pág. 427 (455 ss.); del mismo autor, "Über den Grundsatz der Gewaltenteilung in Deutschland und Europa”, JöR 49 (2001), pág. 287 (296 ss.); A.V. ArNaUld, "Gewaltenteilung jenseits der Gewaltentrennung. Das gewaltenteilige System in der Bundesrepublik Deutschland", ZfParlR 2001, pág. 678; R. WANK, "Gewaltenteilung", Jura 1991, pág. 622 (624 ss.); W.R. WREGE, "Das System der Gewaltenteilung im Grundgesetz", Jura 1996, pág. 436.

9 En este sentido también: U. Di Fabio, "Gewaltenteilung", en: J. Isensee/P. KirchHof (eds.), Handbuch des Staatsrechts, vol. II, 3. ed. 2004, \$27, marginal 4.

10 Sobre la utilización como garantía del núcleo, infra, II. 4. Más ejemplos: BVerfGE 52, 1 (41) (obligación de concretar un supuesto legal de autorización); BVerfGE 9, 89 (102); 96, 375 (394) (límites a la interpretación legal por parte del juez especializado); BVerfGE 4, 331 (347); 10, 200 (216 ss.) (prohibición de la unión personal entre administración y jurisdicción). El infrecuente intento de indicar sentencias del Tribunal Constitucional Federal en las que éste recurra a este principio de forma concreta, directa y relevante para la decisión en M. SACHS, en: SACHS, Grundgesetz-Kommentar, 4. ed. 2007, Art. 20, marginal 93, en la nota 23.

11 Sobre los planteamientos científicos que van más allá del análisis de la jurisprudencia, por ejemplo respecto al potencial iuscomparativo y teórico-legitimador de la organización de poderes: C. MöLLERS, Gewaltengliederung, 2005.

12 Sobre este modo de proceder: P. LERCHE, "Stil und Methode der verfassungsrechtlichen Entscheidungspraxis", Festschrift 50 Jahre BVerfG, vol. I, 2001, pág. 333 (343).

13 M. SACHS, en: SACHS, Grundgesetz-Kommentar (nota 10), Art. 20, marginales 79 ss.; H. Schulze-Fielitz, en: Dreier, Grundgesetz-Kommentar, vol. II, 2. ed. 2006, Art. 20 (Estado de Derecho), marginales 67 ss.; C. Degenhart, StaAtsrecht I, 22. ed. 2006, págs. 113 ss.; J. Ipsen, Staatsrecht I, 18. ed. 2006, págs. 197 ss.; K.-P. Sommermann, en: v. Mangoldt/Klein/Starck, Grundgesetz-Kommentar, vol. II, 5. ed. 2005, Art. 20, marginales 197 ss.; K. STERN, Staatsrecht der Bundesrepublik Deutschland, vol. I, 2. ed. 1984, págs. 792 ss.; H. MAurer, Staatsrecht I, 4. ed. 2005, págs. 379 ss.; lo comentan, no obstante, de manera independiente R. Herzog, en: Maunz/Dürig, Grundgesetz-Kommentar (marzo 2007) Art. 20 V; H.D. Jarass/B. Pieroth, Grundgesetz für die BRD, 9. ed. 2007, Art. 20, marginales 23 ss. 
tado de Derecho, como si no se tratase de una norma independiente ${ }^{14}$. Aquí subyace la vieja idea de que la organización de poderes sirve para disciplinar, moderar y plasmar jurídicamente un poder político originariamente prelegal, una visión evidentemente surgida del cofre predemocrático de los tesoros del Derecho del Estado monárquico ${ }^{15}$ : el que la política democrática se construye sólo a través de la forma jurídica permanece oculto en este contexto ${ }^{16}$. La limitación del poder por medio del Derecho es también necesaria en el Estado constitucional democrático. Sin embargo, esto no basta para desglosar desde la perspectiva jurídico-constitucional la idea de la organización de poderes, porque el Estado democráticamente legitimado también aspira a una organización del poder que sea expresión de y haga realidad la voluntad democrática. La organización de poderes está, por ello, también al servicio de la creación de una organización capaz de imponerse, que será la única que haga posible el gobierno democrático. En el Estado democrático, el Derecho no sólo hace posible la libertad ante el poder característica del Estado de Derecho, sino también la libertad mediante el gobierno democrático de los libres e iguales ${ }^{17}$, lo que ha de ser tenido en cuenta al intentar comprender la norma constitucional central de organización del artículo 20.2.2 GG.

La relación entre el principio democrático y la organización de poderes está siendo lógicamente objeto de un reconocimiento cada vez mayor por parte de la doctrina ${ }^{18}$. De todos modos, en la jurisprudencia del Tribunal Constitucional Federal está todavía poco articulada. En su aplaudida fórmula relativa a la ordenación constitucional de funciones declaró el Tribunal: "La democracia que ha plasmado la Ley Fundamental es una democracia con los caracteres propios del Estado de Derecho, y eso significa ante todo, en la relación de los órganos del Estado entre sí, una democracia que divide el poder ${ }^{19}$. Con esta fórmula el Tribunal vincula de manera clara la organización de

14 En este sentido también: K. SoвотA, Das Prinzip Rechtsstaat, 1997, págs. 70 ss., con referencias adicionales. Relativiza la relación: P. Kunig, Das Rechtsstaatsprinzip, 1986, págs. 153 ss. Cfr. también BVerfGE 22, 44 (54); 34, 52 (59 y siguiente).

15 C. SCHÖnBERGER, Das Parlament im Anstaltsstaat, 1997.

16 En este sentido, por ejemplo, E.-W. BöcKENFörDE, "Demokratie als Verfassungsprinzip", en: J. IsEnsEe/P. KirchHof (eds.), Handbuch des Staatsrechts, vol. I, 1. ed. 1987, 』 22, marginal 92.

17 C. STARCK, "Grundrechtliche und demokratische Freiheitsidee", en: J. IsENSEE/P. KIRCHHOF (eds.), Handbuch des Staatsrechts, vol. II, 1987, \& 29, marginales 1 ss. Crítico, sin embargo, H. DrEIER, "Die drei Staatsgewalten im Zeichen von Europäisierung und Privatisierung", DÖV 2002, pág. 537 ( 537 , nota 5).

18 En primer lugar U. SCHEunER, Verantwortung und Kontrolle in der demokratischen Verfassungsordnung, en: Staatstheorie und Staatsrecht, 1978, pág. 293 (307 y siguiente); K. Hesse, Grundzüge des Verfassungsrechts der Bundesrepublik Deutschland, 20. ed. 1995, marginal 499; H.D. Horn, Die grundrechtsunmittelbare Verwaltung, 1999, págs. 260 ss.; P. LERCHE, Gewaltenteilung - deutsche Sicht, en: J. IsENSEE (ed.), Gewaltenteilung beute, 2000, pág. 75 (78); E. SCHMIDTAßmann, Das allgemeine Verwaltungsrecht als Ordnungsidee, 2. ed. 2004, págs. 179 ss.; SchulzEFIELITZ (nota 13), marginal 67; Heun, Staatshaushalt (nota 3), págs. 97 y siguiente; BöCKENFÖRDE, Demokratie (nota 16), § 22 marginal 87; Di FABIO, Gewaltenteilung (nota 9), marginales 9 y siguiente; en contra, M. ReInHARDT, Konsistente Jurisdiktion, 1997, págs. 48 y siguiente; cfr. también BVerfGE 56, 54 (81).

19 BVerfGE 68, 1 (86 y siguiente) (la cursiva es del Tribunal Constitucional Federal). 
poderes sólo con el Estado de Derecho y la sitúa frente al principio democrático. Esta visión se queda corta, como ya se ha señalado. Una comprensión de la organización de poderes que haya de englobar a los tres Poderes, es decir, también al Poder Legislativo democráticamente legitimado de manera inmediata, puede renunciar tan poco al factor democrático que hace posible el gobierno como al elemento de limitación de la autoridad característico del Estado de Derecho.

\section{DistribuCIÓN ORGÁNICA ADECUADA A LA FUNCIÓN}

Como muy tarde desde la República de $\operatorname{Weimar}^{20}$ ha dejado la doctrina del Derecho del Estado de concebir la organización de poderes sólo como el principio de separación de los poderes. También aquí se manifiesta la necesidad de no reducir su significado a la limitación del poder característica del Estado de Derecho. A diferencia de lo que ocurría en la etapa del constitucionalismo, la Constitución no ubica a una Justicia independiente, un Ejecutivo monárquico y un Parlamento democráticamente legitimado uno al lado de los otros como cuerpos aislados y desvinculados. Con la idea de la distribución orgánica adecuada a la función se ha consolidado más bien un concepto que permite procesar las reglas concretas de la Constitución, en especial la interrelación entre Parlamento y Gobierno en la democracia parlamentaria, y tener en cuenta las tareas específicas de los órganos constitucionales de la Ley Fundamental ${ }^{21}$. En palabras del Tribunal Constitucional Federal, ya mencionadas anteriormente, se dice en este sentido: «...; [la diferenciación y separación de los poderes, C.M.] tiene también como objetivo el que las decisiones estatales sean tomadas de forma en la mayor medida posible correcta, es decir, que lo sean por los órganos que, de acuerdo con su organización, composición, función y modo de proceder, estén en las mejores condiciones para ello.... ${ }^{22}$. De este modo se adopta una primera toma de posición, pero no se dice mucho más ${ }^{23}$, porque en esta fórmula y en su aplicación se presupone la existencia de criterios de "corrección" o de "funcionalidad", pero éstos ni se desarrollan ni se fundamentan. Ahora bien, para desarrollar una fundamentación y un diseño de tales criterios de adecuación no se puede recurrir a

20 Sobre la etapa del constitucionalismo S. Ковіотн, "Monarchisches Prinzip und Gewaltenteilung - unvereinbar?", Der Staat 37 (1998), pág. 27.

21 Básicos: R. Thома, "Die Funktionen der Staatsgewalt”, en: G. Anschüтz/R. Thоma (eds.), Handbuch des Deutschen Staatsrechts, vol. I, 1931, pág. 108 (124 ss.); O. KüsTER, "Das Gewaltenproblem im modernen Staat", AöR 75 (1949), pág. 397 (401 ss.), desarrollados en R. PITSCHAS, Verwaltungsverantwortung und Verwaltungsverfahren, 1990, págs. $536 \mathrm{ss}$. Al respecto también T. von Danwitz, "Der Grundsatz funktionsgerechter Organstruktur", Der Staat 35 (1996), pág. 329 (334 ss.); K. Stern, Staatsrecht (nota 13), vol. II, 1980, págs. 521 ss. Históricos: Achterberg, Funktionenordnung (nota 3), págs. 10 y siguiente; Jarass, Politik und Bürokratie (nota 3), págs. 13 y siguiente; cfr. también G. JELLINEK, Allgemeine Staatslehre, 3. ed. 1912, pág. 596.

22 BVerfGE 68, 1 (86), reiterada en BVerfGE 95, 1 (15); 98, 218 (251 y siguiente).

23 En este sentido también: Heun, Staatshaushalt (nota 3), pág. 89. 
teoremas organizativo-sociológicos o a un análisis de costes y beneficios, aunque precisamente los conceptos empleados, como funcionalidad o corrección, parecen apuntar hacia esta posibilidad. La funcionalidad en el sentido que aquí se reclama sólo puede derivarse normativamente de los preceptos de la Ley Fundamental, es decir, como se desarrollará más en detalle, de los niveles de significado de las nociones de Estado de Derecho y de democracia. Hasta ahora hay, sin embargo, relativamente pocas referencias que permitan una deducción sistemática de tales parámetros. Con la referencia a los requisitos de una decisión "correcta" por medio de la adecuación funcional el problema de la organización de poderes en la Ley Fundamental queda simplemente apuntado, pero no solucionado.

\section{LA GARANTía DEL NÚCLEO Y LA SEPARACIÓN DE PODERES}

La doctrina de la atribución orgánica adecuada a la función queda perfilada en su aplicación, que no en su origen, de forma más concreta en la teoría del núcleo, que el Tribunal Constitucional Federal aplica a diferentes Poderes $^{24}$. La adecuación funcional de la organización estatal queda garantizada por el hecho de que a los órganos constitucionales de la Ley Fundamental se les asegura un mínimo de competencias que sólo ellos pueden asumir ${ }^{25}$. Como hija de la doctrina de la distribución orgánica adecuada a la función adolece la teoría del núcleo, en cualquier caso, de los mismos problemas. ¿De dónde proceden los criterios para la definición de los poderes? El que la argumentación con núcleos en la jurisprudencia del Tribunal Constitucional Federal tenga al final, con frecuencia, una cierta plausibilidad parece que se debe no tanto a la fuerza argumentativa del topos "núcleo" sino más bien a que se está acostumbrado a una determinada concepción tradicional del reparto de trabajo de forma estructurada entre los Poderes. Sin embargo, aunque el Consejo Parlamentario constituyente tenía a su disposición modelos más que de sobra procedentes de la historia política de la ideas cuando aprobó la Ley Fundamental ${ }^{26}$, tales reminiscencias no satisfacen las exigencias

24 La fórmula del núcleo se halla en particular en las BVerfGE 9, 268 (280); 34, 52 (59): «El núcleo de los distintos Poderes es inalterable,; 95, 1 (15). Sobre el núcleo de la responsabilidad ejecutiva resultan básicas las BVerfGE 67, 100 (139); 110, 199 (214), relativa a una comisión de investigación, en conexión con R. ScHOLZ, "Parlamentarischer Untersuchungsausschuß und Steuergeheimnis", AöR 105 (1980), pág. 564 (598), pero propuesto aquí más bien como un límite al abuso ("exceso"). Con carácter general, sin embargo, para el Poder Exterior: 68, 1 (86 y siguiente); 90, 286 (389): “ámbito propio"; 95, 1 (16). La expresión ya no encuentra aplicación, no obstante, en la BVerfGE 104, 151, una sentencia con un supuesto de hecho muy similar a la BVerfGE 68, 1. Más en las BVerfGE 22, 49 (77 y siguiente); 103, 111 (137), ambas sobre la definición del Poder Judicial. BVerfGE 34, 52 (59), sobre los límites a la delegación legislativa.

25 Incluso la pregunta de si las tareas nucleares han de ser, de verdad y sin excepción, siempre asumidas por el órgano competente queda sin respuesta en estas fórmulas. Así resulta que en la formulación hay mucha flexibilidad y muy poco contenido normativo.

26 V. Отто, Das Staatsverständnis des Parlamentarischen Rates, 1971, págs. 92 ss. 
constitucionales de fundamentación. Lo que sí puede más bien la idea del núcleo es señalar de forma inmediata límites convincentes al abuso, pero no es adecuada para proporcionar una base a una sistemática de la organización de poderes en la Ley Fundamental ${ }^{27}$.

La consecuencia jurídica de la garantía del núcleo reclama una asunción autónoma, aunque no exclusiva, de una determinada función por un determinado órgano. En esta medida parece sugerir una separación de los poderes. La jurisprudencia del Tribunal Constitucional Federal insiste desde sus comienzos, en cualquier caso, en que la organización de poderes no exige una separación, sino una limitación y un control mutuos de los distintos poderes ${ }^{28}$. A pesar de esta limitación, la idea de la separación de poderes tiene también en la jurisprudencia una relevancia que no hay que minusvalorar: garantiza la diferenciabilidad práctica de los distintos órganos, lo que adquiere una importancia propia en la valoración jurídico-constitucional de las incompatibilidades $^{29}$. En ningún otro grupo de supuestos aplica el Tribunal la figura de la organización de poderes con tanta frecuencia, en particular para la interpretación del artículo 137.1 GG $\mathrm{GG}^{30}$. A la organización de poderes se recurre regularmente como argumento de refuerzo para declarar su inconstitucionali$\mathrm{dad}^{31}$. En algunas sentencias desempeña incluso un papel decisivo que va más allá del tenor literal de la Constitución ${ }^{32}$. Por medio de esta manera de argumentar se vinculan el mandato de separación y el de control, de modo que aquél hace éste posible ${ }^{33}$.

\section{CONCLUSIÓN INTERMEDia}

Así pues, se puede hacer el siguiente balance intermedio: una comprensión sistemática de la organización de poderes viene exigida en la práctica en particular para poder entender y criticar cómo el Tribunal Constitucional Federal maneja argumentativamente el principio. Se corresponde además con la posición autónoma del principio en el artículo 20.2.2 GG. El principio expresa algo más que la mera suma de los preceptos de la Ley Fundamental en materia de organización y procedimiento. Para desarrollar una concreción de este principio en el contexto del Estado constitucional democrático no es, sin embargo, posible limitar su función al aspecto de control del poder caracte-

27 En este sentido también: Lerche, Gewaltenteilung (nota 18), pág. 82.

28 En primer lugar BVerfGE 3, 225 (247). En conexión con ésta, BVerfGE 7, 183 (188); 9, 268 (279 y siguiente); 22, 106 (111); 34, 52 (59 y siguiente), 95, 1 (15).

29 En este sentido también: C. Sснмттт, Verfassungslebre, págs. 186, 189 y siguiente.

$30 \mathrm{Al}$ respecto G. LÜBBe-WolfF, en: DreIER, Grundgesetz-Kommentar, vol. III, 1. ed. 2000, Art. 17, marginales 7 ss.

31 BVerfGE 12, 73 (77); 38, 326 (338 y siguiente); 40, 296 (321); 42, 312 (338); 57, 43 (62); 58, 177 (201); 98, 145 (160).

32 Claramente en BVerfGE 18, 172 (183): "No es compatible con el principio de la división de poderes..."; de manera similar BVerfGE 48, 64 (83).

33 Así BVerfGE 98, 145 (160). 
rístico del Estado de Derecho, sino que habrá más bien que retrotraer la deducción a las dos decisiones básicas de la Ley Fundamental en favor del Estado de Derecho y la democracia. La referencia a ambas hará posible asignar criterios constitucionales manejables, que hasta ahora son reconocibles, como mucho, en sus rudimentos, a la extendida doctrina de la atribución orgánica adecuada a la función y de la garantía de núcleos funcionales.

\section{UN ANÁLISIS SISTEMÁTICO DE LA ORGANIZACIÓN DE PODERES EN LA LEY FUNDAMENTAL}

\section{Sobre la inTERPRETACiÓN DEL ARTÍ́CUlo 20.2.2 GG: LA ORGANIZACIÓN DE PODERES}

El artículo 20.2.2 GG sitúa el ejercicio del poder estatal alemán en manos de órganos especiales de la legislación, la autoridad ejecutiva y la jurisdicción. Por medio de la Ley Fundamental se diferencian con carácter obligatorio tres formas de autoridad estatal ${ }^{34}$ y se asignan a determinados órganos. La Ley Fundamental divide, por tanto, el poder estatal sin separar los poderes entre sí. En la Ley Fundamental no se encuentra la idea de una organización estatal "fraccionada", tampoco como regla recóndita que sólo se haga realidad con excepciones $^{35}$. El tercer Poder se separa ciertamente de los otros, artículo 97 GG. El primer y el segundo Poder están, sin embargo, expresamente vinculados el uno al otro, artículo 63.1 GG. Por esta razón debería hablarse del principio de la organización constitucional de poderes. Los conceptos "división" y "Separación" no se corresponden con la Ley Fundamental ${ }^{36}$. También la noción de la "adecuación funcional" resulta inapropiada en la Ley Fundamental. El texto de la Ley Fundamental habla de "poderes", no de funciones. La adecuación funcional es, además, una expresión que suena muy técnica, que parece estar orientada sólo hacia la eficiencia, y que no se puede traducir para su uso en Derecho comparado. En adelante se empleará, en consecuencia, por estos motivos, la noción de "organización de poderes" para designar el contenido normativo de la Ley Fundamental. La cuestión decisiva que se le plantea a una dogmática de la organización de poderes y que no se puede responder de manera inmediata recurriendo al artículo 20.2.2 GG es según qué criterios se puede articular una clasificación entre los tres Poderes y los órganos a ellos asignados.

34 Esta expresión ya en SснмiтT, Verfassungslehre (nota 29), pág. 186: “diferenciación de poderes".

35 Así, sin embargo, por ejemplo: BVerfGE 3, 225 (247); 7, 183 (188); 34, 52 (59). Crítico como aquí: Heun, Staatshaushalt (nota 3), pág. 95.

36 También así: ACHTERBERg, Funktionenordnung (nota 3), págs. 109 y siguiente; A. VoßKUHLE, Rechtsschutz gegen den Richter, 1993, pág. 34, nota 2, en ambos casos con referencias adicionales. 
Un primer paso interpretativo orientado en función de la posición sistemática y el tenor literal del artículo 20.2.2 GG excluye ya desde el principio ciertas lecturas habituales de la organización de poderes o, al menos, las relativiza. La organización de poderes de la Ley Fundamental no supone ninguna forma de compensación social del poder. La organización de poderes no garantiza forma alguna de igualdad y equilibrio entre fuerzas sociales o entre sus posibilidades de influir en el proceso democrático. Si bien en la doctrina es posible encontrar a veces aproximaciones que conciben la organización de poderes de esta forma ${ }^{37}$, tal comprensión suprime la diferenciación constitucional entre libertad privada y competencia soberana, ignora la posición sistemática del artículo 20.2 GG como norma especial del Estado y priva al principio de este modo de todo contorno ${ }^{38}$. La organización de poderes se dirige sólo al poder estatal, y si bien pueden producirse mediatamente otros efectos, los mismos no vienen ordenados por la norma.

También los intentos de comprender conceptualmente la organización constitucional de poderes por medio de categorías generales pero desconocidas como tales en la Ley Fundamental, como eficiencia, control, moderación, limitación, mesura, constitución o equilibrio del poder estatal, o fracasan o siguen quedando demasiado poco definidas ${ }^{39}$. Tales conceptos pueden describir determinados elementos del sistema constitucional, pero ni las normas de la Ley Fundamental pueden reducirse a uno de estos conceptos ni los mismos vienen inmediatamente exigidos por ésta. Como siempre, hay que tener cuidado también aquí con la independización de una construcción conceptual que no está orientada ni en función del texto de la norma ni de la sistemática de la Ley Fundamental en su conjunto, sino que generaliza interrelaciones concretas. No es casualidad que tales conceptos se desarrollen regularmente con motivo de una investigación sobre sólo uno de los tres Poderes ${ }^{40}$. La organización constitucional de los poderes conoce, sin duda, muchos tipos de efectos contradictorios: la limitación del ejercicio del poder tanto como su configuración o el hecho de hacerlo posible, la generación de conflictos pero también su resolución. Todo esto no aparece en los conceptos mencionados.

37 Así, en su conjunto poco precisos: J. BeCKer, Gewaltenteilung im Gruppenstaat, 1986, págs. 177 ss.; W. WeBER, "Die Teilung der Gewalten als Gegenwartsproblem", en: Festschrift für Carl Schmitt, 1959, pág. 253. Diferenciador como aquí Di FABIO, Gewaltenteilung (nota 9), marginales 14 ss. En correspondencia con la limitación de la actividad soberana aquí defendida rechaza el Tribunal Constitucional Federal la figura del reparto "publicista" de poder: BVerfGE 73 , 118 (175); 83, 238 (304).

38 J. ISENSEE, "Grundrechte und Demokratie. Die polare Legitimation im grundrechtlichen Gemeinwesen", Der Staat 20 (1981), pág. 161; C. Möllers, Staat als Argument, 2000, págs. 297 ss., con referencias adicionales.

39 En detalle: MölLeRs, Gewaltengliederung (nota 11), págs. 81 ss.

40 Cfr. por ejemplo: JaRAss, Politik u. Bürokratie (nota 3); VoßkuHLe, Rechtsschutz (nota 36). 


\section{Democracia y Estado de Derecho}

Las coordenadas normativas centrales de un desarrollo sistemático del principio de la organización de poderes se hallan en los principios democrático y del Estado de Derecho ${ }^{41}$. Otros principios del artículo 20 GG o tienen otro contenido normativo no referido a la organización, como el principio del Estado social, o pueden, como el principio del Estado federal, ser puestos en relación con la organización de poderes sólo una vez que se haya clarificado su contenido ${ }^{42}$. Los fundamentos de la organización de poderes, válidos también, por vía del artículo 28.1.1 GG, para los Länder ${ }^{43}$, se presuponen primero para ambos niveles federales y serán después modificados por el principio del Estado federal.

Democracia y Estado de Derecho no mantienen ninguna relación de primacía entre sí, sino que ambos tienen el mismo valor normativo ${ }^{44}$. De este modo, las exigencias democráticas y del Estado de Derecho se complementan mutuamente en un nivel constitucional teórico: la forma jurídica puede aspirar a alcanzar reconocimiento sólo porque ha surgido en un proceso democrático. La legitimidad democrática se genera, al revés, sólo por la vía del respeto a las reglas que conforman la democracia, como, por ejemplo, la garantía de un derecho de sufragio libre e igual, una vulneración de la cual traería como consecuencia no sólo la ilegalidad, sino también la pérdida de la pretensión de legitimidad democrática ${ }^{45}$. Esta relación de complementariedad se manifiesta en particular en las leyes parlamentarias, que son en igual medida expresión del Estado de Derecho y de la democracia $^{46}$. A pesar de ello, el principio democrático y el del Estado de Derecho pueden entrar en contradicción a nivel operativo, por ejemplo cuando la Administración ejecuta la voluntad democrática expresada en la ley pero esta ejecución se ve demorada o paralizada por un recurso planteado por un particular ${ }^{47}$.

El principio democrático obliga a atribuir toda actuación estatal a un proceso igualitario y colectivo de formación de la voluntad, artículo 20.2.1 GG. La autodeterminación colectiva es su punto de partida. El principio del Estado de Derecho opera a primera vista de manera más compleja, por no decir difusa. Un denominador común que abarque todos los contenidos que

41 Supra, II., 2.

42 Infra, V., 1.

43 Hasta ahora indiscutido: BVerfGE 2, 307 (319); H. DreIER, en: Dreier, GrundgesetzKommentar, vol. II, 2. ed. 2006, Art. 28, marginal 65, con referencias adicionales.

44 Preciso: BöCKENFÖRDE, Demokratie (nota 16), marginal 87.

45 Una fundamentación teórica concisa en J. HABERMAS, «Über den internen Zusammenhang von Rechtsstaat und Demokratie", en: Die Einbeziehung des Anderen, 1999, pág. 293. Cfr. también O. GerstenBERg, Bürgerrechte und deliberative Demokratie, 1997.

46 BÖCKENFÖRDE, Demokratie (nota 16), marginal 35; P. BADURA, en: Bonner Kommentar (agosto 2007), Art. 38, marginal 13; Schulze-Fielitz (nota 13), Art. 20 (democracia), marginal 67.

47 BöCKenförde, Demokratie (nota 16), marginal 92; SCHMidT-AßMAnN, Rechtsstaat (nota 6), marginal 96. 
se le atribuyen es, en parte, objeto de discusión ${ }^{48}$. Sus diferentes facetas (desde la reserva de ley para limitar los derechos fundamentales, a la garantía de la tutela judicial, pasando por la garantía de una protección elemental de los derechos fundamentales, el principio de proporcionalidad, y la independencia de los Tribunales ${ }^{49}$ ) pueden reconducirse todas ellas, no obstante, a la protección de la percepción individual de libertad ${ }^{50}$. Si bien el principio del Estado de Derecho como tal es un principio constitucional objetivo $^{51}$, para dotar a sus contenidos reconocidos de un contexto sistemático hay que situarse en la perspectiva de un sujeto individual de derechos ${ }^{52}$. Éste puede, gracias al principio del Estado de Derecho, esperar del ejercicio del poder soberano ciertas cualidades, como la previsibilidad por medio de la seguridad jurídica, la legalidad o el rigor formalista, así como un control judicial independiente de estas cualidades en relación a su propia posición jurídica.

Para la dogmática de la organización de poderes, las implicaciones procedimentales y jurídico-organizativas de esta interrelación son decisivas, porque ahora puede comprenderse la relación complementaria y contradictoria entre el principio democrático y el del Estado de Derecho como un medio que posibilita la autodeterminación individual y democrática. El principio de la organización de poderes sirve, desde esta perspectiva, para asegurar la organización y el procedimiento de actuación estatal en un modo que reconozca en igual medida la protección de la libertad individual, característica del Estado de Derecho, y la autodeterminación democrática colectiva, que las exprese y que dirima las contradicciones mediante procedimiento y organización. A falta de una relación de primacía entre democracia y Estado de Derecho, la solución a las contradicciones se deja en manos de los procedimientos de la organización de poderes.

\section{El artículo 20.2.2 GG COMO REGLA ORIENTADA POR LA AUTODETERMINACIÓN}

El artículo 20.2.2 GG garantiza, por tanto, una conformación de la organización y del procedimiento estatales que haga posible y proteja la coexistencia de ambas formas de autodeterminación, la libertad individual y el autogobierno democrático ${ }^{53}$. Fundamento de ambas formas de autodeterminación es la

48 Kunig, Rechtsstaatsprinzip (nota 14).

49 Schmidt-Aßmann, Rechtsstaat (nota 6), marginales 69 ss.

50 Sobre las conexiones: Hesse, Grundzüge (nota 18), marginal 191; SCHMidT-AßMANN, Rechtsstaat (nota 6), marginales 30 y siguiente; STERN, Staatsrecht (nota 13), págs. 788 ss.

51 Hesse, Grundzüge (nota 18), marginales 186 ss.

52 Sobre las correspondientes raíces históricas de la reserva de ley para limitar derechos fundamentales, característica del Estado de Derecho: D. JEsch, Gesetz und Verwaltung, 2. ed. 1968, págs. 156 ss.

53 Más en detalle: Möllers, Gewaltengliederung (nota 11), págs. 29 ss. 
personalidad del ser humano ${ }^{54}$ postulada por el artículo 1.1 GG, que le atribuye una capacidad de decisión autónoma que puede hacer realidad tanto de forma individual, para sí mismo, artículo 2.1 GG, como de forma colectiva, en tanto que parte del sujeto de legitimación democrática, artículo 20.2.1 GG. Del papel fundamental de la dignidad humana se deriva pues, como punto de partida, un individualismo normativo ${ }^{55}$. Éste no implica, sin embargo, la primacía de la autodeterminación individual frente a la democrática, sino que ambas se basan en un concepto de personalidad protegido por la dignidad humana ${ }^{56}$.

El ordenamiento jurídico protege la libertad individual mediante disposiciones organizativas y procedimentales que deciden con alcance individualizado, de forma retrospectiva y sobre la base sólo de criterios jurídicos. La autodeterminación individual necesita de la coacción jurídica sólo cuando ya ha sido articulada y choca con un obstáculo a su realización que sea eliminable mediante medios jurídicos ${ }^{57}$. El ordenamiento jurídico no puede, por el contrario, presuponer la formación democrática de la voluntad: ésta sólo podrá articularse en un ordenamiento jurídico que, mediante reglas de libertad y de igualdad, transforme una expresión colectiva cualquiera de voluntad en una voluntad democrática imputable, populismo en autodeterminación democrática ${ }^{58}$. La formación de la voluntad democrática no sólo es culturalmente más rica en requisitos, sino también institucionalmente más difícil de articular que la protección de la voluntad individual. Como forma de expresión del sujeto democrático de legitimación resulta potencialmente omnicomprensiva, general e inclusiva; prospectiva en tanto que conformación abierta de la voluntad democrática; y estará materialmente predeterminada por el Derecho sólo en la menor medida posible ( $s i$ no, ya no podríamos hablar de formación de la voluntad ${ }^{59}$ ).

Tanto en la Ley Fundamental como en la jurisprudencia del Tribunal Constitucional Federal se encuentran numerosos puntos de referencia para estos criterios funcionales, que se refieren al alcance regulativo, a la intensidad de la vinculación jurídica y a la orientación temporal, y que remiten a los criterios básicos de la actuación jurisdiccional y legislativa. Tales criterios alcan-

54 Sobre la interrelación entre dignidad humana y organización de poderes también: Di FABIO, Gewaltenteilung (nota 9), marginal 2.

55 D.v.D. Pfordten, "Normativer Individualismus und das Recht”, JZ 2005, pág. 1069.

56 C. ENDERs, Die Menschenwürde in der Verfassungsordnung, 1997, págs. 391 y siguiente; H. Dreier, en: Dreier, Grundgesetz-Kommentar, vol. I, 2. ed. 2004, Art. 1 I, marginal 40; C. STARCK, en: v. MANGOLDT/KieIn/STARCK, Grundgesetz-Kommentar, vol. I, 5. ed. 2005, Art. 1, apartado 1, marginal 7; H. Hofmann, "Die versprochene Menschenwürde", AÖR 118 (1991), pág. 353 (355 y siguiente); O. LEPSIUs, Steuerungsdiskussion, Systemtheorie und Parlamentarismuskritik, 1999, págs. 53 ss.

57 A este respecto en detalle: MöLlers, Gewaltengliederung (nota 11), págs. 41 ss.

58 Sobre los límites constitucionales de esta decisión: E. Laclau, On Populist Reason, 2005.

59 Sobre la relación entre transcurso del tiempo y organización de poderes: G. HusserL, Recht und Zeit, 1955, págs. 54 ss.; H. Hofmann, Das Recht des Rechts, das Recht der Herrschaft und die Einheit der Verfassung, 1998, págs. 43 y siguiente; P. KIRCHнOF, "Verwalten und Zeit - Über gegenwartsbezogenes, rechtzeitiges und zeitgerechtes Verwalten (1975)", en: Streitige Verfassung und politische Erneuerung, 1995, pág. 73 (75 y siguiente): "Zeitschema der Gewaltenteilung»; G. DüRIG, "Zeit und Rechtsgleichheit", en: Festschrift Tübinger Juristenfakultät, 1977, pág. 21 (37 ss.). 
zan, sin embargo, un perfil sistemático propio sólo por la vía de su igual vinculación al Estado de Derecho y a la democracia. En el artículo 19.1.1 GG se expresa una gradación, característica de la organización de poderes, del alcance objetivo de las decisiones estatales. Una orientación temporal graduada se manifiesta en el diferente peso que la prohibición de la irretroactividad tiene para los tres Poderes ${ }^{60}$, pero también en el límite a la anticipación de decisiones legislativas o ejecutivas por parte del Poder Judicial ${ }^{61}$. Una gradación de la vinculación jurídica del Legislativo al Judicial se muestra, por un lado, en que se deja expresamente abierta, en los artículos 21.1.1 y 38.1.2 GG, la formación de la voluntad democrática; por otro, en el artículo 97 GG; y en la plasmación jurídica, ordenada por el artículo 19.4 GG, de los estándares de actuación soberana precisamente cuando se trata de juzgar posiciones jurídicas individuales. La Ley Fundamental conoce, además, niveles intermedios entre los dos polos de la generación democrática de Derecho y de la protección individualizada de la libertad. La organización de poderes exige, por tanto, también formas intermedias en las que ambos tipos de legitimidad sean tomados en consideración de forma gradual, de modo que los tres Poderes puedan quedar implicados en una relación continuada de concreción desde lo materialmente abierto a lo jurídicamente determinado, desde lo más general desde un punto de vista material y personal a alcances normativos particulares, y desde lo prospectivo a lo retrospectivo ${ }^{62}$.

De acuerdo con este modo de entender las cosas, el artículo 20.2.2 GG protege la tarea procedimental democrática y del Estado de Derecho de los órganos constitucionales, y asegura una asignación de estructuras decisorias que garantice que para ambas aspiraciones existirán procedimientos y organizaciones a disposición que puedan ser adecuadamente asignados desde el punto de vista de la legitimidad. El alcance material, la orientación temporal y el grado de plasmación jurídica de los parámetros decisorios son los criterios a través de los cuales se logra la legitimidad.

\section{4. ¿EL ARTículO 20.2.2 GG COMO PRINCIPIO CONSTITUCIONAL?}

La distinción entre reglas y principios ${ }^{63}$ ha penetrado en el Derecho de la organización del poder público ${ }^{64}$ procedente de la dogmática de los derechos

60 H. Maurer, "Kontinuitätsgewähr und Vertrauensschutz", en: J. IsEnSEe/P. KirchHOF (eds.), Handbuch des Staatsrechts, vol. III, 1988, \& 60, marginales 10, 65, 100. Una "gradación propia de la división de poderes" para un caso particular en C. WALDHOFF, "Vertrauensschutz im Steuerrechtsverhältnis", en: H.-J. PEZzER (ed.), Vertrauensschutz im Steuerrecht, 2004, pág. 129 (132 ss.)

61 Infra, IV., 2., b).

62 Cfr. también Heun, Staatshaushalt (nota 3), pág. 101.

63 R. Dworkin, Taking Rights Seriously, 1977.

64 V. Mende, "Regeln und Prinzipien im Recht der Staats- und Verwaltungsorganisation", Die Verwaltung 34 (2001), pág. 93. De forma análoga se aplican los principios del artículo 20 GG en el trabajo de K.-E. HaIn, Die Grundsätze des Grundgesetzes, 1999 (sobre la división de poderes: págs. 353 y siguiente). 
fundamentales ${ }^{65}$. Ahora bien, esta distinción alcanza un significado propio sólo si los principios constitucionales se interpretan como mandatos de optimización. Junto a objeciones más básicas ${ }^{66}$ se plantea en particular la pregunta de cómo puede entenderse una norma de Derecho procedimental y organizativo como un mandato de optimización. La idea de una conformación del procedimiento susceptible de ser optimizada contradice la idea, positivizada en el artículo 20.2.2 $\mathrm{GG}^{67}$, de una producción jurídica basada en un reparto del trabajo. La organización de poderes no conoce ningún punto arquimédico desde el que se pueda definir y poner en funcionamiento la mejor organización estatal posible, sino que más bien se deja esta determinación a la cooperación y al enfrentamiento entre los tres Poderes. Con ello se ubica dentro del sistema una dinámica que resulta del todo ajena a la búsqueda, propia de la teoría jurídica de los principios, focalizada en la jurisdicción (constitucional), de la mejor solución material posible ${ }^{68}$. En vez de como principio, la organización de poderes ha de entenderse como una norma secundaria ${ }^{69}$, procedimental $^{70}$, como una norma que regula la producción jurídica y que con ello participa de la mutabilidad del ordenamiento jurídico. En definitiva, el artículo 20.2.2 GG no es ningún "principio" en el sentido de la doctrina jurídico-teórica de los principios, sino que, más bien al contrario, su contenido regulativo estaría en contra de la aplicabilidad de la teoría de los principios del Derecho a la Ley Fundamental, o, más aún, a cualquier ordenamiento jurídico en el que los poderes estén organizados.

\section{5. ¿QUUE ORGANIZA LA ORGANIZACIÓN DE PODERES?}

¿Qué modo de proceder se estructura mediante la organización constitucional de poderes? La respuesta de las doctrinas clásicas de la división de poderes remitía al ejercicio del poder. Ésta no es, claramente, una solución jurídicamente útil. El poder es la ampliación de un ámbito subjetivo de actuación que no se sirve necesariamente de formas jurídicas ${ }^{71}$. El poder, por

65 R. AleXY, Theorie der Grundrechte, 1986.

66 Referencias y críticas a la idea de optimización en P. LeRche, "Die Verfassung als Quelle von Optimierungsgeboten?", en: Festschrift für Klaus Stern, 1997, pág. 197 (204 ss.). En especial para la organización de poderes: LerCHE, Gewaltenteilung (nota 18), págs. 83 ss. Sobre la crítica a la equiparación de los principios constitucionales con su idoneidad para la ponderación: F. REINER, Verfassungsprinzipien, 2001, págs. 174 ss.

67 Una crítica similar en relación al papel del legislador en M. JESTAEDT, Grundrechtsentfaltung im Gesetz, 1999, págs. 206 ss.

68 JESTAEDT, Grundrechtsentfaltung (nota 67). Esta focalización judicial resulta clara en los orígenes de la teoría de los principios: R. Dworkin, Taking Rights Seriously, 1977; del mismo autor, Law's Empire, 1986.

69 En el sentido de H.L.A. Hart, The Concept of Law, 1961, págs. 77 ss.

70 Sobre la interrelación entre organización y procedimiento que queda de este modo englobada: S. BAER, "Vermutungen zu Kernbereichen der Regierung und Befugnissen des Parlaments", Der Staat 40 (2001), pág. 525 (541, nota 81, con referencias adicionales).

71 Sobre el concepto de poder, una valiosa visión general en B.-C. HaN, Was ist Macht?, 2005. 
ejemplo en el ámbito político, no puede identificarse simplemente con la forma jurídica. Para una comprensión constitucional de la organización de poderes hay que encontrar otro vinculo, lo cual sugiere referir la organización de poderes a la producción de Derecho. En contra de un uso lingüístico ampliamente extendido, los Tribunales, pero también los órganos de la Administración, no sólo aplican Derecho, sino que todos los Poderes aportan más bien una contribución independiente a la producción de Derecho: una sentencia de un Tribunal o un acto administrativo no suponen tampoco una aplicación no autónoma de la ley, sino una concreción con carácter decisorio propio y consecuencias jurídicas propias, y, en esa medida, comparable en categoría a la legislación ${ }^{72}$. Esto explica por qué es necesaria una organización de poderes. Si las Administraciones y los Tribunales fuese autómatas aplicadores del Derecho, uno podría limitarse simplemente a equiparar por completo el Ejecutivo y el Judicial como modalidades de aplicación jurídica e ignorar los diferentes procedimientos y estándares de organización de ambos $^{73}$.

Esta comprensión jurídico-teórica precisa una transposición constitucional. En primer lugar, el poder del Estado, es decir, toda actuación imputable con carácter decisorio $^{74}$, hay que entenderlo, como en el caso del principio democrático, como elemento característico del supuesto de hecho de la organización de poderes. Al examinar el efecto generador de Derecho de los tres Poderes también se aprecia más claramente la aplicación de los criterios que se desarrollaron anteriormente: alcance, orientación temporal e intensidad de la plasmación jurídica son criterios que ponen en relación el procedimiento y la organización de la producción jurídica con el contenido normativo del Derecho producido. ¿̇upone esta conexión que la actuación informal queda fuera del alcance de la organización de poderes? No es posible dar una respuesta válida con carácter general a esta pregunta, aunque sólo sea porque la noción de lo informal es demasiado difusa ${ }^{75}$. También la actuación informal puede tener consecuencias jurídicas y estar subordinada, por ejemplo como injerencia puntual en los derechos fundamentales, a las exigencias de la organización de poderes. La vinculación con la producción jurídica no supone tampoco, a la inversa, que elementos informales de la fase de preparación no puedan quedar también protegidos por la organización de poderes. Así se pone de manifiesto, por ejemplo, en la formación, abierta e informal, de la voluntad

72 Básico: A. MerkL, Die Lehre von der Rechtskraft entwickelt aus dem Rechtsbegriff, 1923, págs. 81 ss.; al respecto JESTAEDT, Grundrechtsentfaltung (nota 67), págs. 279 ss.

73 La dicotomía estática entre creación jurídica y aplicación del Derecho y el problema que de aquí se deriva de cómo se puede diferenciar el Ejecutivo del Judicial han ocupado durante mucho tiempo partes de la teoría; cfr. por ejemplo M. TROPER, La séparation des pouvoirs et l'histoire constitutionelle française, 1972, págs. 142 ss.

74 BVerfGE 83, 60 (73).

75 Sobre las diferenciaciones: C. MölLers, "Methoden”, en: W. HofFMANN-RIEm/E.SCHMIDT-AßMANN/A. VoßKuHLE (eds.), Grundlagen der Verwaltungsrechtswissenschaft, vol. I, 2006, $₫ 3$, marginal 15 . 
parlamentaria, que hay que preservar de una plasmación jurídica demasiado intensa para hacer posible la formación democrática de la voluntad ${ }^{76}$.

\section{CONCLUSIÓN INTERMEDiA}

El artículo 20.2.2 GG, el principio de la organización constitucional de poderes, representa una norma autónoma de organización que engrana organizativa y procedimentalmente la protección de la libertad individual característica del Estado de Derecho y la autodeterminación democrática colectiva. La referencia a ambas formas de libertad, individual y democrática, permite desarrollar ciertos criterios para la definición de los tres Poderes que se refieren al alcance de su actuación, la intensidad de la plasmación jurídica y la orientación temporal. De este modo se excluyen tanto una reducción de la organización de poderes sólo a mecanismos propios del Estado de Derecho o a la capacidad democrática de actuación como una expansión de este principio procedimental, que difumine sus contornos, a cuestiones de corrección o legalidad materiales.

\section{LOS TRES PODERES Y SUS INTERRELACIONES JURÍDICAS}

La comprensión de la organización constitucional de poderes así deducida ha de verse reflejada en la práctica. Para ello, en primer lugar, hay que definir los tres Poderes como tales en más detalle (1.). A continuación podrán elaborarse criterios para explicar las relaciones jurídicas existentes entre ellos (2.).

\section{Sobre la definición del Poder Legislativo, Ejecutivo y Judicial}

La necesidad de definir Poder Legislativo, Ejecutivo y Judicial se plantea en la práctica con poca frecuencia y en diferente medida según el Poder de que se trate, si miramos el material casuístico constitucional. La necesidad de una definición depende también de qué formas jurídicas haya a disposición del ordenamiento constitucional para facilitar la definición de un Poder.

\section{a) Poder Legislativo}

En la práctica se necesita un concepto constitucional de legislación con tan poca frecuencia porque las normas constitucionales relativas al procedimiento legislativo parlamentario y a la forma jurídica de la ley hacen 
posible en la mayor parte de los casos una fácil identificación del Poder Legislativo ${ }^{77}$. La Constitución conecta las numerosas consecuencias jurídicas de la forma de ley, en concreto la pretensión de vinculación general del artículo 20.3 GG, con las reglas democráticas de creación, organización y procedimiento del Bundestag alemán y con las normas de los derechos fundamentales de comunicación y del Derecho de los partidos políticos, que protegen la formación de la voluntad democrática ${ }^{78}$. Sólo las normas aprobadas en el marco del procedimiento legislativo de acuerdo con los artículos 76 y siguientes de la Ley Fundamental pueden ser las del Poder Legislativo ${ }^{79}$. El legislador democrático se debe sólo a un procedimiento y a una forma de decisión, la ley ${ }^{80}$.

Con ello, sin embargo, no se ha dicho todavía nada acerca de cuándo las leyes aprobadas por el Bundestag alemán se apartan tanto del concepto de legislación que vulneran el artículo 20.2.2 GG. Una respuesta a esta pregunta obliga a desarrollar criterios más amplios. De la referencia a la autodeterminación democrática que caracteriza a estos criterios se deriva que el Legislativo debería ser una modalidad del Derecho orientada hacia el futuro, reguladora con el grado de generalidad más elevado posible, y que resulte de un procedimiento de representación abierto y general. La argumentación no puede, sin embargo, detenerse en este punto, sino que para la definición de la noción de legislación resulta más bien decisivo el hecho de que el carácter abierto de la formación de la voluntad democrática, como se desprende de los artículos 21.1 y 38.1.2 GG, garantice a la vez que el ideal constitucional teórico de una ley general y orientada al futuro no pueda acceder de forma ilimitada a la plasmación jurídica ${ }^{81}$. La noción de ley así definida representa una opción del Poder Legislativo que le brinda la Constitución, pero no una obligación. Dicho de otra manera: del principio de la organización de poderes se deriva que los órganos legislativos han de estar autorizados para aprobar leyes generales y orientadas hacia el futuro, pero no que estén obligados a respetar siempre estos criterios. De otro modo el carácter abierto de la formación de la voluntad democrática quedaría anulado por un concepto constitucional de ley. El artículo 20.2.2 GG no ordena la aprobación de leyes generales que re-

77 H. Heller, "Der Begriff des Gesetzes in der Reichsverfassung", VVDStRL 4 (1928), pág. 98; cfr. sin embargo el reciente caso BVerfGE 114, 196.

78 H. Schulze-Fielitz, Theorie und Praxis parlamentarischer Gesetzgebung, 1988, págs. 184 ss.

79 A. GREIFELD, Volksentscheid durch Parlamente, 1983, págs. 95 ss.

80 Así la conocida constatación en el trabajo de W. GEIGER, "Gegenwartsprobleme der Verfassungsgerichtsbarkeit aus deutscher Sicht", en: T. BERBERICH (ed.), Neue Entwicklungen im öffentlichen Recht, 1979, pág. 131 (141).

81 Teóricamente: H. Hofmann, "Postulat der Allgemeinheit des Gesetzes ", en: C. STARCK (ed.), Die Allgemeinheit des Gesetzes, 1987, págs. 9 ss. (39 y siguiente); N. ACHTERBERG, "Kriterien des Gesetzesbegriffs unter dem Grundgesetz", DÖV 1973, pág. 289 (293 y siguiente); del mismo autor, Funktionenordnung (nota 3), págs. 204 y siguiente; sobre el criterio, trazado en la Ley Fundamental, pero no positivizado, de la generalidad: C. STARck, Der Gesetzesbegriff des Grundgesetzes, 1970, págs. 185 ss. 
nuncien a su carácter de compromiso político ${ }^{82}$. De acuerdo con esto, todos los intentos de elaborar una noción jurídica de ley general han fracasado, no sólo en la dogmática constitucional alemana ${ }^{83}$. Un concepto de ley general formulado de manera muy estricta, susceptible de ser examinado por los Tribunales, limitaría la formación de la voluntad democrática de manera contraria a la función que ha de cumplir.

La organización de poderes exige, además, someter de manera selectiva la formación de la voluntad democrática, en el acto de la elección y en el procedimiento parlamentario, a vínculos constitucionales ${ }^{84}$. Esto ha de ocurrir allí donde la pretensión de legitimidad de la ley misma quede conformada por medio del Derecho, en particular mediante el aseguramiento de iguales oportunidades de participación política, cosa que sucede especialmente en el Derecho electoral y en el Derecho de los partidos políticos. Pero los mandatos constitucionales de optimización de la legislación no se derivan precisamente del artículo 20.2.2 GG. Al contrario, las obligaciones del legislador de observación de la realidad social o de mejora de la legislación, así como los procedimientos que permitan valorar las consecuencias de la ley como plasmación jurídica de la formación de la voluntad política se hallan tendencialmente en contradicción con la organización de poderes de la Ley Fundamental y han de justificarse o limitarse respetando este principio ${ }^{85}$.

La noción de la generalidad de la ley alcanza sólo en conexión con otros criterios un perfil más ajustado que va más allá de lo aquí desarrollado. Hay que poner límites a la legislación formal allí donde el legislador eluda completamente al Ejecutivo y defina posiciones jurídicas individuales inmediatas sin dejar al segundo Poder competencias decisorias propias. Los artículos 19.1.186 y 19.4 GG confirman esta conclusión. Estos artículos suponen concreciones de la prohibición que se deriva del artículo 20.2.2 GG de excluir por medio de la ley al Poder Judicial. Una ley que eluda al Ejecutivo y al Judicial vulnera el mandato, que se deriva de la organización de poderes, de la concreción jurídica continuada que incluya a los tres Poderes. Vulnera el artículo 20.2.2 $\mathrm{GG}^{87}$. Similares consecuencias se derivan de la orientación 218).

82 Expresamente de otro modo, pero para un supuesto especial: BVerfGE 101, 158 (214 ss.,

83 BVerfGE 25, 371 (398 y siguiente), 95, 1 (14 ss.). Cfr. también sobre la precisión: O. LEPSIUS, "Die erkenntnistheoretische Notwendigkeit des Parlamentarismus", en: M. BERTSCHI y otros (eds.), Demokratie und Freiheit, 1999, págs. 123, 168 y siguiente, en la nota 127.

84 Di FABIO, Gewaltenteilung (nota 9), marginal 21.

85 Cfr. sin embargo BVerfGE 88, 203 (309 ss.); 93, 37 (84 y siguiente); 94, 115 (151 y siguiente); 97, 271 (294 y siguiente). En este sentido también: G. SCHWERDTFEGER, "Optimale Methodik der Gesetzgebung als Verfassungspflicht", en: Festschrift für Hans Peter Ipsen, 1977, pág. 173. En sentido similar: J. LÜCKE, "Die Allgemeine Gesetzgebungsordnung”, ZG 2001, pág. 1. Críticos como aquí: C. Gusy, "Das Grundgesetz als normative Gesetzgebungslehre?", ZRP 1985, pág. 291 (296 ss.); S. Huster, “Die Beobachtungspflicht des Gesetzgebers”, ZfRSoz 24 (2003), pág. 3 (11 ss.); experiencias escépticas con la estimación de las consecuencias de la ley en el trabajo de P. Buum, "Wege zu besserer Gesetzgebung, Gutachten I, 65”. DJT 2004, pág. 1 (61 ss.).

86 BVerfGE 85, 360 (374).

87 En otro sentido BVerfGE 95, 1 (15 y siguiente). 
temporal. La importancia, precisamente para el legislador, de la prohibición de la retroactividad ${ }^{88}$, no regulada expresamente en la Constitución, salvo en el artículo 103.2 GG, se puede fundamentar del siguiente modo: también con normas retroactivas abandona el legislador la orientación temporal que la organización de poderes les marca a los Poderes: establece normas para un período de tiempo en el que todavía no había tenido lugar la formación de la voluntad democrática y para el cual el legislador todavía no estaba legitimado.

En definitiva, en la mayoría de los casos la propia forma legal exime de definir lo que es el Poder Legislativo. El mandato de la organización de poderes lo que aporta no son tanto argumentos que limiten normativamente la legislación como una presunción básica, que se inscribe dentro de las normas, constitutivas para la democracia, del Derecho electoral y de los partidos políticos, en favor de una formación de la voluntad democrática, abierta y no normada, que desemboca en la legislación. Sólo cuando el legislador ignora la relación de concreción, eludiendo al Ejecutivo y al Judicial, entran en juego, por efecto de la organización de poderes, criterios más amplios para limitar el Poder Legislativo.

\section{b) Poder Judicial}

La Ley Fundamental encomienda el Poder Judicial a los jueces y Tribunales, artículo 92 GG. Este Poder no se define, pues, como el Legislativo, a través de una forma jurídica («ley"), sino que viene más bien marcado por una decisión organizativa que se vincula a la forma institucional establecida del Tribunal. Una definición del Poder Judicial es, en la práctica, necesaria con más frecuencia que en el caso de los otros dos Poderes, como lo muestra la práctica decisoria, muy rica en comparación con otros ámbitos, del Tribunal Constitucional Federal ${ }^{89}$. La necesidad de una definición constitucional más precisa no se ajusta a la lógica aquí expuesta de la organización de poderes, que plasma jurídicamente en mucha mayor medida la actuación del tercer Poder (y, con ello, también su definición conceptual) de lo que lo hacía en el caso del primer Poder. Además, la Ley Fundamental enlaza en muchas de sus normas con la noción de jurisdicción, tanto en el supuesto de hecho como en las consecuencias jurídicas. De este modo, el artículo 19.4 GG tiene como consecuencia la actuación del Poder Judicial ${ }^{90}$. Éste es, a su vez, elemento del supuesto de hecho de determinados mandatos de organización (artículos 97, 98 GG) y procedimiento (artículos 101, 103.1 GG) ${ }^{91}$.

88 Cfr. supra, III., 3.

89 BVerfGE 7, 183 (188 y siguiente); 8, 197 (207); 12, 264 (274); 22, 49 (73 ss.); 31, 43 (46); 35, 65 (73); 60, 253 (255 ss.); 64, 175 (179); 76, 100 (106); 103, 111 (137 y siguiente).

90 E. Schmidt-Aßmann, en: Maunz/Dürig, Grundgesetz-Kommentar (marzo 2007), Art. 19, apartado 4, marginal 173.

91 SChMidT-AвMann (nota 90), marginal 174. 
De su principal tarea, que es la de proteger la autodeterminación individual, se derivan algunos criterios para una definición del Poder Judicial ${ }^{92}$. La jurisdicción se debe siempre al impulso de la iniciativa ajena: sin demandante no hay juez. La petición del demandante es, pues, constitutiva para la comprensión de la idea de jurisdicción ${ }^{93}$. Los criterios desarrollados más arriba se ajustan en gran medida a lo dicho en la jurisprudencia del Tribunal Constitucional Federal, que procede de forma tópica, y le aportan una fundamentación sistemática: el Derecho como único parámetro para la decisión judicial ${ }^{94}$, la firmeza y fuerza vinculante de las decisiones judiciales ${ }^{95}$, su relación con el caso concreto ${ }^{96}$, y la independencia política de los jueces, todos estos criterios son elementos de una estructura procedimental y organizativa que tiene como objetivo los derechos individuales. Mediante estos criterios se garantiza que se dé respuesta a la petición específica del sujeto individual de Derecho. Se confirman también en Derecho comparado ${ }^{97}$, porque la jurisdicción es, en la tesis que aquí se desarrolla, la resolución, generada a partir exclusivamente de criterios jurídicos, originada a iniciativa de terceros, retrospectiva y definitiva, de peticiones en la mayor medida posible individualizadas, es decir, de casos. Esto se corresponde también con la afirmación del Tribunal Constitucional Federal de que una normativa legal que "prevea un procedimiento judicial de resolución soberana de conflictos y que otorgue efectos jurídicos a las decisiones que hayan de adoptarse en este punto, efectos que sólo pueden producir Tribunales independientes ${ }^{98}$, ha de configurarse en correspondencia con esto, lo cual excluye que una Sala de Justicia pueda estar formada por diputados de un Parlamento regional99.

En relación al criterio de la solución de litigios aparecen divergencias con la jurisprudencia del Tribunal Constitucional Federal y con algunas voces de la doctrina ${ }^{100}$. Así, el Tribunal juzgó que su antigua competencia para la emisión de dictámenes ${ }^{101}$ era «en principio ajena a la función judicial» ${ }^{102}$. Frente a ello

92 MÖLlers, Gewaltengliederung (nota 11), págs. 95 ss. 2006.

93 Para el caso especial de la jurisdicción penal: C. Möllers, Die drei Gewalten, manuscrito,

94 Referencias y críticas en VoßKuHLe, Rechtsschutz (nota 36), págs. 75 ss., en alusión a la formación jurídica de los jueces. Pero también la formación jurídica de los jueces se produce tomando como criterio el Derecho; a diferencia de la producción legislativa, no está vinculada a un proceso político.

95 BVerfGE 7, 183 (188 y siguiente); 31, 43 (46); 60, 253 (269 y siguiente); 103, 111 (137).

96 BVerfGE 103, 111 (137 y siguiente): "en el caso concreto".

97 M. Cappelletti, The Judicial Process in Comparative Perspective, 1988, págs. 30 ss.; M. SHAPIRO, Courts, 1981, págs. 1 ss., 28 ss.

98 BVerfGE 103, 111 (137 y siguiente). Ahora bien, respecto a la mención de la independencia, la frase contiene una petición de principio. De lo que se trata es del contenido de la decisión; sólo a partir de ahí pueden derivarse consecuencias para su organización y procedimiento.

99 BVerfGE 103, 111 (140 y siguiente).

100 Críticas en la BVerfGE 22, 49 (76) a la definición de E. Friesenhahn, “Über Begriff und Arten der Rechtsprechung", Festschrift für Richard Thoma, 1950, pág. 21.

$101 \rrbracket 97$ BVerfGG (antigua versión).

102 Así pues, consecuente: BVerfGE 2, 79 (86), en referencia a la situación americana. Al respecto C. Pestalozza, Verfassungsprozeßrrecht, 3. ed. 1991, págs. 236 y siguiente. 
hay que apuntar que la solución de conflictos no es un rasgo característico exclusivo del Poder Judicial, sino que también resulta conocido para los otros Poderes, en concreto para el Ejecutivo en la vía administrativa previa a la vía judicial o para el Legislativo en el enfrentamiento parlamentario antes de acordar el texto definitivo de la ley. La solución de conflictos es un elemento importante, pero no característico del Poder Judicial. Por eso la doctrina le añade la exigencia de que la resolución sea "neutral" como requisito que definiría a este Poder $^{103}$. Pero con la exigencia de neutralidad en realidad no se describiría nada más que la obligación del Poder Judicial de aplicar estrictamente la ley, sin espacio para la formación de voluntad propia ${ }^{104}$. La ley que hay que aplicar, por el contrario, no es en absoluto neutral, sino el resultado de una decisión política que podría haber acabado siendo otra. La tarea del juez, específica de este Poder, de juzgar con carácter definitivo un supuesto de hecho individualizado exclusivamente según criterios jurídicos no se pone en cuestión, por tanto, por el hecho de que se tenga también competencia para la emisión de dictámenes, siempre que se respeten los presupuestos procesales. Esta perspectiva alcanza un significado propio cuando se aborda el posible diseño de controles judiciales para el ejercicio del Poder Exterior ${ }^{105}$.

\section{c) Poder Ejecutivo}

El artículo 20.2.2 GG emplea un concepto unitario de Poder Ejecutivo, cuya definición plantea tradicionalmente especiales problemas. Como siempre, es habitual una concepción negativa que simplemente "substrae" los otros dos Poderes para determinar qué es el Poder Ejecutivo ${ }^{106}$. También la distinción entre Gobierno y Administración plantea el problema de abarcar de manera unitaria partes muy diversas de la organización estatal, "política y burocracia" 107. Aunque siga siendo un concepto unitario del Poder Ejecutivo, tanto el método de la sustracción como las diferenciaciones mencionadas contienen un núcleo correcto. En ambas se pone de manifiesto la pluralidad organizativa del Poder Ejecutivo —entre el Gobierno Federal configurador político y los funcionarios que ejecutan sin margen de decisión - que asigna al Ejecutivo la tarea de mediar funcionalmente entre los dos polos generadores de Derecho, el Legislativo y el Judicial ${ }^{108}$. No resultan adecuados los intentos de ubicar al Ejecutivo de ma-

103 VoßKuHLe, Rechtsschutz (nota 36), págs. 94 ss.; M. KaUfMann, Untersuchungsgrundsatz und Verwaltungsgerichtsbarkeit, 2002, págs. 203 ss. (tratada aquí como imparcialidad).

104 ACHTERBERG, Funktionen (nota 3), pág. 150.

105 Infra, V., 2.

106 O. MAYER, Deutsches Verwaltungsrecht, vol. I, 3. ed. 1924, pág. 7. Sobre esta discusión: H.J. Wolff/O. Bachof, Verwaltungsrecht, 11. ed. 1999, $\ 2$. Para una definición positiva del Ejecutivo, orientada según el principio de la división de poderes: E. Forsthoff, Lebrbuch des Verwaltungsrechts, 10. ed. 1973, págs. 1 ss.

107 JARASS, Politik und Bürokratie (nota 3).

108 Tal función mediadora se deriva también de la aproximación de M. FeHLING, Verwaltung zwischen Unparteilichkeit und Gestaltungsaufgabe, 2001, págs. 93 ss. 
nera unilateral como conformador político en la cercanía del Legislativo, o como aplicador ligado al Derecho en la cercanía de la jurisdicción ${ }^{109}$, en lugar de entender ambos elementos como partes necesarias del Ejecutivo.

La labor de mediar entre el primer y el tercer Poder implica exigencias graduadas en la tarea de producción jurídica del Ejecutivo en sus distintos niveles. Entre la actuación del Ejecutivo como iniciador de la legislación, artículo 76 (primera alternativa) GG, o como productor de reglamentos, artículo 80.1.1 GG, por una parte, y la decisión de un caso concreto mediante un acto administrativo, por otra, las características funcionales de la producción jurídica ejecutiva oscilan desde lo cuasi-legislativo a lo cuasi-judicial: la intensidad de los vínculos jurídicos aumenta, las decisiones se vuelven más individualizadas, la orientación temporal se acerca al presente, que se alcanza con la "presentificación" (Vergegenwärtigung) de Derecho y realidad en el acto de la ejecución ${ }^{110}$. Finalmente, la actuación ejecutiva en forma de autocontrol, como en el procedimiento administrativo previo a la vía judicial, puede operar también retrospectivamente. La relación entre los distintos niveles de concreción se asegura, con carácter general, mediante una estructura jerárquica en cuya cúspide se sitúa el órgano que es democráticamente responsable omnímodo ${ }^{111}$. Sin embargo, el artículo 20.2.2 GG no exige facultades para impartir instrucciones específicas dentro del Ejecutivo, como sí que se discuten en relación al principio democrático ${ }^{112}$. Y es que la organización de poderes en la Ley Fundamental reclama también la autonomía en la labor de concreción de los distintos niveles ejecutivos que han de especificar de forma continuada las exigencias legales. Esto sugeriría la aplicación de disposiciones administrativas generales, pero no de instrucciones específicas de la cúspide política. El que la resolución de cuestiones concretas quede reservada a una decisión ministerial, con lo que la autodeterminación individual del destinatario se topa de repente con la pretensión conformadora del Gobierno, no es inconstitucional, pero seguramente tampoco responde al ideal del artículo 20.2.2 GG. La expresión "organización de poderes dentro de la Administración, ${ }^{113}$ no quiere decir que haya que erigir barreras organizati-

109 Los teóricos que destacan el carácter político del Derecho Constitucional destacan igualmente las tareas legislativas de la Administración: C. SснмітT, Legalität und Legitimität, 1932; R. SMEND, "Die politische Gewalt im Verfassungsstaat und das Problem der Staatsform” (1923), en: Staatsrechtliche Abhandlungen, 3. ed. 1994, pág. 68 (78 y siguiente). Los teóricos que destacan más bien la juridificación de la política colocan a la Administración en las proximidades de la jurisdicción: H. Kelsen, Die Lebre von den drei Gewalten oder Funktionen des Staates, Kant-Festschrift, 1924, pág. 214 (238).

110 M. JESTAEDT, Das mag in der Theorie richtig sein...: vom Nutzen der Rechtstheorie für die Rechtspraxis, 2006.

111 H. Dreier, "Verantwortung im demokratischen Verfassungsstaat", en: U. NeumanN/ L. Schulz (eds.), Verantwortung in Recht und Moral, 2000, pág. 9 (12 y siguiente).

112 Sobre la situación jurídica, muy discutida, según el principio democrático, una visión general en C. MölLers, "Theorie, Praxis und Interdisziplinarität in der Verwaltungsrechtswissenschaft", Verwaltungs-Archiv 93 (2002), 22 (págs. 31 ss.).

113 Esta idea en el trabajo de W. LEISNER, "Gewaltenteilung innerhalb der Gewalten", en: Festschrift für Theodor Maunz, 1975, pág. 267. 
vas, sino asegurar diferentes niveles autónomos de decisión dentro del Ejecutivo.

El Poder Ejecutivo de la Ley Fundamental, a diferencia de lo que ocurre con los otros dos Poderes, está vinculado sólo a aquellos mecanismos que hacen posible la defensa de la libertad, propia del Estado de Derecho, y la autodeterminación democrática, es decir, a la tutela judicial y a la elección democrática. Por esta razón muestra un mayor continuidad organizativa ${ }^{114}$ y dispone de mayores posibilidades para la especialización interna que los otros Poderes. Puede almacenar y sistematizar el saber de manera más continuada. Por ello existe también en el Estado democrático de Derecho una especial relación entre actuación del Ejecutivo y pericia, lo cual claramente no justifica que el Ejecutivo se independice de la programación democrática y de los controles jurisdiccionales ${ }^{115}$. Sus particularidades organizativas dan a entender, sin embargo, que el Ejecutivo puede aplicar, dentro del respeto a las exigencias legales, también otros criterios de actuación distintos del Derecho $^{116}$. Las capacidades ejecutivas que abre la ley no son, en la organización de poderes, un mal necesario, sino expresión de las especiales posibilidades organizativas de decisión que ofrece el Ejecutivo y que el legislador puede aprovechar para hacer realidad sus objetivos ${ }^{117}$.

La actuación del Ejecutivo está sometida con carácter general a los criterios que vienen fijados en la ley, artículo 20.3 GG. Si bien el Ejecutivo no necesita siempre un fundamento legal para que su actuación sea válida ${ }^{118}$, no hay espacios en los que quede desvinculado de la ley cuando el legislador haya actuado, y ello con independencia de que exista una injerencia en un derecho fundamental. Hay que constatar, no obstante, a la vista de las tendencias más recientes en la jurisprudencia del Tribunal Constitucional Federal $^{119}$, que la Ley Fundamental no conoce una reserva de ley negativa que excluya determinadas materias de la regulación mediante una ley. La ley no representa sólo, como en el Derecho del Estado de la etapa constitucional, un límite, sino también el fundamento de toda actuación ejecuti-

114 Aquí subyace la razón sistemática de la identificación teóricamente discutible, pero muy extendida en los ordenamientos jurídicos continentales, entre "Estado" y Administración. Para el caso de Alemania: Möllers, Staat (nota 38), págs. 230 ss.; para el caso francés: D. Bates, "Political Unity and the Spirit of the Law: Juridical Concepts of the State in the Late Third Republic", French Historical Studies 28 (2005), pág. 69.

115 Por eso continúa sin éxito la búsqueda de la figura jurídicamente relevante de la "autonomía" de la Administración: H. DreIER, "Zur "Eigenständigkeit" der Verwaltung", Die Verwaltung 1992, pág. 137; H. MaureR/F.E. SchNAPP, "Der Verwaltungsvorbehalt”, VVDStRL 43 (1985), pág. 135, 172; KuHL, Kernbereich (nota 5), págs. 141 ss.

116 R. SCHMIDT, "Flexibilität und Innovation im Bereich der Verwaltungsmaßstäbe», en: W. HofFMAnN-Riem/E. SCHMidT-AßMAnN (eds.), Innovation und Flexibilität des Verwaltungshandelns, 1994, pág. 67.

117 SchmidT-Aßmann, Verwaltungsrecht (nota 18), págs. 223 ss.

118 De Administración no sujeta a la ley se podrá hablar sólo cuando la Administración actúe de manera no válida.

119 Así sin embargo: BVerfGE 105, 279 (304); enlazando con ésta: BVerfGE 108, 282 (335) (voto particular discordante de Di Fabio, Jentsch, Mellinghoff). 
$\mathrm{va}^{120}$. Entendida a la luz de la organización de poderes, la reserva democrática de ley determina sólo el "sì de una normativa legal, es decir, la circunstancia de que la actuación legislativa precede a la ejecutiva, pero no compromete el proceso democrático de formación de la voluntad por el hecho de que prescriba cómo de intensa ha de resultar la programación legal. Para ello podrá haber otros criterios, en concreto derivados de los derechos fundamentales ${ }^{121}$.

\section{Relaciones entre los tres Poderes}

La organización de poderes asigna los tres Poderes a determinados órganos y regula las relaciones entre ellos. Especial atención merecen, siguiendo el orden de la concreción jurídica, las relaciones entre el Poder Legislativo y el Ejecutivo (a) y entre el Ejecutivo y el Judicial (b). Las relaciones directas, que no se produzcan por medio del Ejecutivo, entre el Legislativo y el Judicial serán abordadas al analizar la jurisdicción constitucional ${ }^{122}$.

\section{a) Poder Legislativo y Poder Ejecutivo}

Para una dogmática de las relaciones constitucionales entre el Legislativo y el Ejecutivo es decisivo diferenciar entre lo que supone posibilitar la formación informal de la voluntad democrática del Legislativo para la preparación del texto definitivo de la ley y las relaciones jurídicas que se producen a continuación: el artículo 20.2.2 GG protege también, mediante la posibilidad de la formación de la voluntad democrática, todas las posibilidades que tiene el Legislativo de prepararse, por medio del acceso a informaciones diversas, para el diseño democrático de la decisión. Una vez concluido el procedimiento legislativo, el artículo 20.2.2 GG garantiza, no obstante, también una concreción autónoma de la ley por parte del Ejecutivo. Las posibilidades formalizadas de intervención y de influencia del Bundestag en la actuación del Ejecutivo en el sentido de un control parlamentario existen, para la formación de la voluntad democrática del Bundestag, antes de la decisión legislativa, pero no para su ejecución posterior ${ }^{123}$.

En el proceso de formación de la voluntad democrática, el Gobierno Federal asume a través de su derecho de iniciativa legislativa un papel autónomo y significativo en la práctica ${ }^{124}$. Esta tarea no supone una intromisión ne-

120 Formulación: U. Scheuner, “Das Gesetz als Antrag der Verwaltung”, DÖV 1969, pág. 585.

$121 \mathrm{Al}$ respecto infra, IV., 2.

$122 \mathrm{Al}$ respecto infra, VI., 2.

123 Sobre la crítica que de aquí se deriva al vago concepto del "control parlamentario": MöLleRs, Gewaltengliederung (nota 11), págs. 198 ss.

124 K.v. Beyme, Der Gesetzgeber, 1997, págs. 176 ss.; H. Schulze-Fielitz, Parlamentarische Gesetzgebung (nota 78), págs. 285 ss.; H. SCHNEIDER, Gesetzgebungslehre, 3. ed., 2002, págs. 61 ss. 
cesitada de justificación en los dominios del Legislativo, porque también el Gobierno es democráticamente omnicompetente. La participación del Gobierno supone, más aún, no sólo una gran ayuda desde el punto de vista técnico, sino que es también expresión de la responsabilidad democrática global de ambos órganos, querida por la organización de poderes ${ }^{125}$. El trabajo técnico en la ley reclama la participación del Ejecutivo. A la vez, la burocracia ministerial se orienta desde el principio de acuerdo con la formación política de la voluntad en el Bundestag, de modo que no se puede hablar de una simple ratificación parlamentaria de la $\operatorname{ley}^{126}$. Querer reconocer en la cooperación informal de ambos una violación de la organización constitucional de poderes (o simplemente también la expresión de una crisis institucional) supondría comprender básicamente mal el sistema parlamentario de la Ley Fundamental y permanecer prisionero de las categorías del constitucionalismo monárquico ${ }^{127}$.

La formación de la voluntad democrática se ve estimulada por los derechos de intervención del Parlamento que se derivan del artículo 43 GG y, sobre todo, del artículo $38 \mathrm{GG}^{128}$. De las experiencias así difundidas del Ejecutivo aprende el Parlamento para la legislación futura y la opinión pública democrática para futuras elecciones ${ }^{129}$. Lo mismo se puede decir de las comisiones de investigación parlamentarias, que abren a la minoría parlamentaria la posibilidad de acceder a la mayoría democrática ${ }^{130}$. De la organización de poderes no pueden derivarse límites al derecho general de información parlamentaria o a las especiales facultades de investigación de una comisión par-

125 Originariamente la noción de "poder de gobierno" servía para explicar la competencia conjunta de Parlamento y Ejecutivo: M. Troper, "Les relations extérieures dans la constitution de l'an III", en: La Théorie du Droit, Le Droit, L'État, 2001, 129.

126 V. Beyme, Gesetzgeber (nota 124), págs. 143 ss.; M. MorloK, "Informalisierung und Entparlamentarisierung politischer Entscheidungen als Gefährdung der Verfassung?", VVDStRL 62 (2003), pág. 37 (64 ss.)

127 Parece a veces que expresiones doctrinales en sentido opuesto estuviesen hablando del Imperio más que de la Ley Fundamental, así I.v. MüNCH, "Minister und Abgeordneter in einer Person: die andauernde Verhöhnung der Gewaltenteilung", NJW 1998, pág. 34. Contra esto ayuda echar un vistazo a un clásico del sistema parlamentario: W. BAGEHOT, The English Cons. (1867), 1966, pág. 69: "The English system, therefore, is not an absorption of the executive power by the legislative power; it is a fusion of the two" [el sistema inglés, por tanto, no supone una absorción del Poder Ejecutivo por el Poder Legislativo, es una fusión de ambos]. El "English system" designa aquí estructuras que se corresponden con las del artículo 63.1 GG. La idea de que las "auténticas" leyes han de ser no sólo políticamente apoyadas, sino también técnicamente elaboradas en el Parlamento tiene su origen asimismo en la etapa del constitucionalismo histórico, en el que el Parlamento no gobernaba. No es adecuada en un sistema de democracia parlamentaria. Referencias en C. SCHÖNBERGER, "Die überholte Parlamentarisierung. Einflussgewinn und fehlende Herrschaftsfähigkeit des Reichstags im sich demokratisierenden Kaiserreich", HZ 272 (2001), pág. 623 .

128 M. MORLOK, en: DreIER, vol. II, Grundgesetz-Kommentar, 2. ed. 2006, Art. 38, marginal 43.

129 Sobre estas funciones del control parlamentario: P. BADURA, "Die parlamentarische Demokratie", en: J. IsENSEe/P. KirchHOF (ed.), Handbuch des Staatsrechts, vol. II, 3. ed. 2004, \ 25, marginal 12.

130 BVerfGE 105, 197 (222). 
lamentaria ${ }^{131}$. El Gobierno está en principio totalmente obligado a proporcionar información. Sólo pueden justificarse determinados límites, en circunstancias especiales, a partir de la prohibición del abuso de poder ${ }^{132}$. En relación con la jurisdicción, artículo 44.4.2 GG, la organización de poderes ofrece también la protección que brinda la labor individualizadora en que consiste el procedimiento judicial, que no puede asegurar la pretensión de libertad del afectado cuando el material procesal está ampliamente politizado. Estos criterios, aunque puedan fundamentarse a partir de la organización de poderes, pueden, sin embargo, desarrollarse de manera más precisa a través de los derechos subjetivos del afectado ${ }^{133}$.

El artículo 20.2.2 GG ofrece básicamente otros criterios para las relaciones entre el Ejecutivo y el Legislativo una vez aprobado el texto de la ley. En este punto hay que considerar la vinculación general del Ejecutivo a la ley, por una parte, y la autonomía de la labor aplicadora del Ejecutivo, por otra:

En el Derecho de organización no es posible deducir de la Ley Fundamental la aceptación de un "poder de organización" del Gobierno resistente a la ley que excluya al legislador de la configuración de la organización administrativa. Las normas de organización son un instrumento necesario para hacer realidad los objetivos legales, pero precisamente por eso no se puede privar de ellas al legislador $^{134}$. La autonomía que hay que reconocerle al segundo Poder no es una autonomía al margen de la ley, sino dentro de ésta. Esto no significa, sin embargo, que el Ejecutivo deba esperar al legislador organizador para poder actuar. Al margen de la reserva institucional de ley, que es necesaria porque la creación de nuevos sujetos de Derecho necesita una legitimación democrática ${ }^{135}$, el Ejecutivo puede organizarse a sí mismo, siempre que el legislador omita esta actuación ${ }^{136}$. El artículo 86.2 GG muestra en este sentido que el legislador puede configurar la organización de las administraciones, pero no tiene por qué hacerlo necesariamente ${ }^{137}$. La noción de "poder de organización" presupone, por el contrario, una competencia que enfrentaría al Parlamento y al Gobierno y que resultaría ajena al sistema parlamentario ${ }^{138}$, por lo que hay que renunciar a ella.

131 Sobre la obligación de respuesta del Gobierno Federal: BVerfGE 13, 123 (125), que se corresponde con BVerfGE 57, 1 (5); 67, 100 (129); 80, 188 (218); 105, 252 (270); 105, 279 (306).

132 En este sentido por última vez también: BVerfGE 110, 199 (214 ss.).

133 Sobre esto J. MASING, Parlamentarische Untersuchungen privater Sachverhalte, 1998.

134 Sobre el significado del Derecho de organización para lograr los objetivos del legislador cfr. por todos los trabajos en: W. Hoffmann-Riem/E. SchmidT-Aßmann (ed.), Verwaltungsorganisationsrecht als Steuerungsressource, 1997.

135 G. C. BurmeIsTER, Herkunft, Inhalt und Stellung des institutionellen Gesetzesvorbebalts, 1991, págs. 241 ss.

136 BAER, Vermutungen (nota 70), pág. 525.

137 G. Hermes, en: Dreier, Grundgesetz-Kommentar, vol. III, 1. ed. 2000, Art. 86, marginales 61 y siguiente.

138 Esto se documenta de manera impresionante en la crítica de D. JEsch, "Recensión", $A$ öR 85 (1961), pág. 484, a E.-W. BÖCKENFÖRDE, Die Organisationsgewalt im Bereich der Regierung: eine Untersuchung zum Staatsrecht der Bundesrepublik Deutschland, 1. ed. 1961. Sobre las raíces constitucionales de la discusión resulta convincente: H. BuTzer, "Zum Begriff der Organisationsgewalt", Die Verwaltung 27 (1994), pág. 157 (158 ss.). 
Otra cosa resulta de aplicación al poder de designación de cargos propio del Ejecutivo. Los actos de nombramiento son, en principio, en tanto que decisiones individuales concretas, en todo caso asunto del Ejecutivo, porque corresponden, por debajo del nivel político, a la dimensión personal de la concreción legislativa. El artículo 20.2.2 GG excluye un derecho autónomo del Bundestag para designar o bloquear quién ha de ocupar cargos ejecutivos, como muestran también el artículo 64.1 GG y el derecho de nombramiento del Presidente Federal del artículo 60.1 GG. Esta idea se deduce también del hecho de que el artículo 20.3 GG no conoce ningún derecho parlamentario general de participación más allá de la ley. Un nombramiento parlamentario de funcionarios en los niveles más bajos, quienes sólo asumen una responsabilidad fragmentaria, contradiría la misión graduada de concreción del Ejecutivo que se refleja en la jerarquía. Por tanto, derechos de codecisión en los nombramientos serán constitucionalmente inadmisibles en la medida en que los nombrados se hallen en una relación de responsabilidad respecto a un Ministro.

Otras conexiones jurídicamente articuladas entre el Legislativo y el Ejecutivo han de justificarse a la luz del artículo 20.2.2 GG. El que los gremios de control de autoridades independientes o de empresas estatales estén formados por miembros del Bundestag, como ocurre por ejemplo en el $₫ 5.1$ de la Ley de la Agencia Federal para la Electricidad, el Gas, las Telecomunicaciones, Correos y los Ferrocarriles (Gesetz über die Bundesnetzagentur für Elektrizität, Gas, Telekommunikation, Post und Eisenbahnen, BNetzAgenturG), es cuestionable desde el punto de vista constitucional ${ }^{139}$ porque los Diputados individuales en tales gremios, a diferencia de lo que ocurre en las Comisiones parlamentarias, ni siquiera producen legitimidad parlamentaria, que sólo puede surgir coram pleno et publico. Aquí asumen tareas ejecutivas, por tanto, integrantes del Legislativo, que no pueden generar legitimidad legislativa. Dado que las tareas de las unidades organizativas afectadas están definidas de manera estricta y se hallan en una relación competencial y de subordinación jerárquica específica sería más apropiado desde el punto de vista funcional el que los gremios de control estuviesen compuestos por funcionarios.

Los procedimientos administrativos pueden regularse mediante una ley parlamentaria, pero no tienen por qué serlo necesariamente ${ }^{140}$. También aquí es aplicable, en referencia a la labor graduada de concreción del Ejecutivo entre ley democrática y sentencia judicial, que cuanto más se acerque el procedimiento administrativo a esferas jurídicas individuales protegidas por el Estado de Derecho, más se exige la regulación legal de las garantías procedimentales ${ }^{141}$.

$139 \mathrm{Al}$ respecto H. C. RöBl, Regierungs- und Verwaltungsbefugnisse des Parlaments, manuscrito 2002, en el punto III.

140 A diferencia de lo que ocurre en el ámbito del Derecho de organización, la cuestión de la reserva de ley para el procedimiento, según hemos podido ver, no ha sido apenas tratada.

141 Esto se manifiesta también en el surgimiento jurisprudencial de obligaciones procedimentales, como las exigencias de motivación o de audiencia, que fueron siempre desarrolladas para decisiones concretas. Una comparación en MöLleRs, Gewaltengliederung (nota 11), págs. 117 y ss. 
Esta idea ha sido, por ejemplo, incorporada al $\delta 9$ de la Ley de Procedimiento Administrativo (Verwaltungsverfabrensgesetz, $\mathrm{VwVfG}$ ) con la referencia al acto administrativo $^{142}$. Por el contrario, cuanto más cerca se halle el procedimiento del proceso democrático de formación de la voluntad, menos exigencias procedimentales habrán de imponérsele. La tendencia a la plasmación jurídica, mediante derechos de audiencia y de consulta ${ }^{143}$, de los procedimientos de elaboración de normas por parte del Ejecutivo suscita algunos reparos porque con ello la responsabilidad democrática global del Gobierno se somete a una plasmación jurídica sólo particular. Además, desaparecen las posibilidades, propias del Ejecutivo, para una toma rápida de decisiones ${ }^{144}$. La atribución de una decisión ejecutiva al Gobierno responsable omnímodo es un argumento a favor del reconocimiento de más márgenes procedimentales al titular de la potestad reglamentaria, pero no a favor de un procedimiento postlegislativo en pequeño. En el caso de la subdelegación de competencias, artículo 80.1.4 GG, estos argumentos pierden peso gradualmente, lo cual es un indicio de un alcance menor del objeto de regulación y, con ello, también a favor de la introducción de procedimientos participativos. Lo mismo es aplicable a otras formas del reglamento, como en Derecho regional de policía. Las subdelegaciones pueden aportar un indicio de que la forma reglamentaria no resulta adecuada para el objeto concreto de regulación ${ }^{145}$. El artículo 20.2.2 GG exige una elección de la forma jurídica adecuada desde el punto de vista de la legitimidad ${ }^{146}$, es decir, por ejemplo para proyectos definidos objetiva y espacialmente no la forma reglamentaria sino un procedimiento más estrechamente integrador de los intereses en juego vía aprobación de planes de proyectos públicos (Planfeststellung), ordenanzas municipales o actos-resoluciones de alcance general (Allgemeinverfügung). La plasmación jurídica del procedimiento de aprobación de reglamentos aparece, por el contrario, como expresión de una desconfianza alarmante del Parlamento frente a los propios mecanismos democráticos de legitimación.

$142 \mathrm{Al}$ respecto P. Stelkens/H. Schmitz, en: Stelkens/Bonk/Sachs, VwVfG, 6. ed. 2001, $₫ 9$, marginales 98 ss.

143 A este respecto E. Hagenah, Prozeduraler Umweltschutz, 1996, págs. 114 ss.; C. LeitzKe, Die Anhörung beteiligter Kreise nach $\mathbb{I S} 51$ BimschG, $60 \mathrm{KrW} / \mathrm{AbfG}, 17 \mathrm{Abs} .7 \mathrm{ChemG}, 6 \mathrm{WRMG}$, 20 BbodSch G, 1999; G. LÜBBe-WolfF, "Verfassungsrechtliche Fragen der Normsetzung und Normkonkretisierung im Umweltrecht, $Z G 6$ (1991), pág. 219. Fundamental: C. GößWEIN, Allgemeines Verwaltungs(verfahrens)recht der administrativen Normsetzung?, 2001.

144 LEPSIUS, Parlamentarismus (nota 83), págs. 171 y siguiente; en otro sentido, desde una perspectiva de Derecho comparado: S. Rose-ACKerman, Umweltrecht und-politik, 1995, págs. 257 ss.

145 Para el ejemplo de la fijación de rutas de vuelo según los \$\$ 32.1.1 de la Ley de Tráfico Aéreo (Luftverkehrsgesetz, LuftVG) y 27a.2.1 del Reglamento de Tráfico Aéreo (Luftverkehrsordnung, LuftverkehrsO): A. KuKK, "Rechtsschutz von Flughafenanwohnern gegen die Festlegung von Flugrouten: Zwei Schritte vor, ein Schritt zurück", NVwZ 2001, pág. 408 (409). Cfr. respecto a las obligaciones de ponderación del titular de la potestad reglamentaria: VGH Kassel, NVwZ 2003, pág. 875 (878 y siguiente). Un mero control de la arbitrariedad, por contra, en BVerwGE 111, 276 (283).

146 Cfr. frente a esto muy reticente, sin ser tampoco convincente: BVerfGE 106, 275 (307 y siguiente) sobre la elección del acto-resolución de alcance general (Allgemeinverfügung) para la fijación de importes fijos. 
La participación del Bundestag en la aprobación de reglamentos no está prevista en la Ley Fundamental ${ }^{147}$. Desde la perspectiva de la organización de poderes retoma el Bundestag en este sentido el procedimiento legislativo democrático ya concluido, después de que el Ejecutivo haya llevado a cabo, con la presentación de un reglamento, una labor autónoma de concreción, lo cual ha de ser en principio valorado de forma diferente a como se haría si el Bundestag hubiese adoptado desde el primer momento la norma correspondiente. El legislador revisa sus propias decisiones para un caso especial ad hoc. La legitimidad democrática del reglamento no aumenta por la participación ${ }^{148}$, el Derecho constitucional no conoce un "más" o un "menos" de legitimidad democrática, sino un "sí se tiene" o "no se tiene" "149. O el reglamento carecía en todo caso de legitimidad democrática por falta de precisión de la autorización legal según el artículo 80.1.2 GG, o la legitimidad del reglamento no estaba, a través de la autorización del Bundestag, ni necesitada de mejora ni era susceptible de mejora. Estos planteamientos, pero también el problema de la ausencia de posibilidad jurídica de clasificar los reglamentos que han sido modificados por el Parlamento ${ }^{150}$, inclinan la balanza en favor de reconocer en toda participación del Bundestag en el ejercicio de la potestad reglamentaria una vulneración del artículo 20.2.2 GG.

Desde el punto de vista de la dimensión jurídico-material, la delegación de competencias legislativas del Legislativo al Ejecutivo no representa una ruptura del artículo 20.2.2 GG $^{151}$, sino que más bien el legislador expresa también mediante la delegación una voluntad democrática específica de configuración que puede obedecer a motivos políticos o prácticos dignos de reconocimiento. Los límites abstractos a la delegación, controlables por los Tribunales, resultan más bien cuestionables a la luz del artículo 20.2.2 GG. Es el propio legislador democrático el que ha de perfilar los márgenes de actuación del Ejecutivo de forma apropiada a la situación concreta, sin estar por ello sometido a un ideal de legislación jurisdiccionalmente controlable para el

147 En la doctrina: A. Uhle, Parlament und Rechtsverordnung, 1999, págs. 289 ss.; J. SснміDт, Die Beteiligung des Bundestages beim Erlaß von Rechtsverordnungen, 2002, págs. 56 ss.

148 En este sentido K.-P. SOMmermanN, "Verordnungsermächtigung und Demokratieprinzip", JZ 1997, pág. 434 (438); P. Henseler, "Die Grundrechtsbindung des Verordnungsgebers", ZG 1986, pág. 76 (78). La idea aparece ya en BVerfGE 8, 274 (320): "Los reglamentos que exigen para su aprobación el respaldo expreso del Bundesrat (Zustimmungsverordnungen) .... implican, no obstante, un déficit en comparación con la plena delegación de la legislación en el Ejecutivo".

149 Convincente: A. v. BoGDANDy, "Demokratisch, demokratischer, am demokratischsten?", en: Festschrift für Alexander Hollerbach, 2001, pág. 363.

150 Claramente en BVerfGE 114, 196. Dado el origen meramente consuetudinario del hecho de permitir los reglamentos que exigen para su aprobación el respaldo expreso del Bundesrat (Zustimmungsverordnungen), las soluciones de la mayoría y la minoría de la Sala resultan en este punto insatisfactorias; al respecto en detalle C. Möllers, "Formloser Sozialstaat gegen rechtsstaatliche Form - Zustimmungsrechte des Bundesrats und Rechtsverordnungsänderung durch den Bundestag", Jura 2007.

151 Cfr. respecto a esta afirmación ampliamente extendida, por todos: RAUSCHNING, Regierungssystem (nota 2), pág. 228, con referencias jurisprudenciales adicionales, por ejemplo BVerfGE 18, 52 (59). 
que, también en Derecho comparado, se encuentran criterios poco consistentes. Otra cosa puede afirmarse sólo cuando los presupuestos de hecho de la delegación dejen dudas acerca del alcance de los derechos individuales. En este caso entran en juego los mandatos de plasmación jurídica inducidos a partir de la idea de Estado de Derecho, pero entonces los derechos fundamentales suministran también criterios operativos para fijar los límites a la delegación. A la luz de la interpretación del artículo 80.1.2 GG es, en este sentido, correcto desde el punto de vista lógico el que el Tribunal Constitucional Federal incluya en la interpretación la posible afectación del ámbito de protección de derechos fundamentales y la previsibilidad de la injerencia ${ }^{152}$. También la muy vituperada reserva de ley respecto a las normas "esenciales para el ejercicio de derechos fundamentales" ${ }^{153}$ resulta plausible desde este punto de vista ${ }^{154}$. La organización de poderes exige, como el Tribunal Constitucional Federal lo formuló tempranamente, "que el legislador, en el ámbito del ejercicio de los derechos fundamentales, delimite la esfera jurídica que queda abierta a la posible injerencia del Estado..." ${ }^{155}$. Así pues, la organización de poderes promueve, precisamente desde el respeto hacia la decisión democrática concreta del legislador, el que el Derecho constitucional se limite a una reserva de ley propia del Estado de Derecho.

\section{b) Poder Ejecutivo y Poder Judicial}

El control judicial de la Administración precisa, como procedimiento exigido por el Estado de Derecho, un diseño detallado por parte del legislador. Sólo con cautela se le podrán poner límites a este diseño que vayan más allá de la garantía de tutela judicial del artículo 19.4 GG.

La fijación de la intensidad del control judicial corresponde ante todo al legislador ${ }^{156}$. No está plenamente determinada por el artículo 19.4 GG aunque sólo sea porque el alcance de los derechos subjetivos que presuponen esta norma, incluidos los derechos fundamentales, han de ser configurados por el

152 Fórmulas de libertad de decisión, programa y previsibilidad que se derivaban del mandato de una legislación "clara". En esta línea jurisprudencial se hallan las BVerfGE 1, 14 (60); 2, 307 (334 y siguiente); 4, 7 (20); 5, 71 (76 y siguiente); 7, 282 (291 ss.); 8, 274 (307 ss.); 19, 354 (361); 23, 62 (72). Sobre el abovedado material adicional de la jurisprudencia posterior: $\mathrm{H}$. Bauer, en: Dreier, Grundgesetz-Kommentar, vol. II, 2. ed. 2006, Art. 80, marginales 33 ss. Ejemplos son las BVerfGE 41, 251 (265 y siguiente); 48, 210 (221 y siguiente); 58, 257 (276), 102, 197 (222).

153 Respecto a la crítica, por todos: M. KLOEPFER, JZ 1984, págs. 689 ss., con referencias adicionales; sobre el necesario desarrollo posterior de la dogmática: K.-H. LadeuR/T. GostomzYK, "Der Gesetzesvorbehalt im Leistungsstaat", Die Verwaltung 36 (2003), pág. 141 (160 ss.).

154 BVerfGE 33, 125 (157 ss.); 33, 303 (345 y siguiente); 40, 237 (248 y siguiente); 47, 46 (78 y siguiente); 49, 89 (126 y siguiente); 57, 295 (319 y siguiente); 88, 103 (116); 95, 267 (307); 98, 218 (251); 100, 1 (32 y siguiente).

155 BVerfGE 20, 150 (158 y siguiente). Al respecto, fundamental: W. KreBs, Vorbehalt des Gesetzes und Grundrechte, 1975, págs. 110 ss.

156 Básico: E. SchmidT-Aßmann (nota 90), marginales 185 ss. 
legislador ${ }^{157}$. Por una parte, el mandato de la actuación conforme a las exigencias del Estado de Derecho sugeriría un control según criterios jurídicos en especial de aquellas actuaciones administrativas que afectan a derechos subjetivos. Por otra parte, la estructura autónoma organizativa y procedimental del Ejecutivo no puede reproducirse discrecionalmente en un procedimiento judicial, especialmente cuando el legislador no le ha señalado a la Administración criterios no jurídicos de actuación dentro del marco de estándares jurídicos ${ }^{158}$. Este reparto de trabajo puede operar también en interés de los individualmente afectados, que tendrán por ejemplo un derecho a un procedimiento en el que disfruten de iguales oportunidades (p. ej. examen de Estado) o un interés en recibir un tratamiento adecuado a la situación en que se hallen (p. ej. discrecionalidad, en las normas de policía ${ }^{159}$, pero que con ello aspiran a una actuación del Ejecutivo que no puede ser plenamente reproducida por un Tribunal ${ }^{160}$. Las estructuras ejecutivas autónomas de toma de decisiones dentro del orden de la organización de los poderes respetan tanto la configuración democrática con forma de ley del Ejecutivo como las inquietudes individuales del destinatario de la actuación administrativa ${ }^{161}$. De la organización de poderes no se deriva la obligación de un control jurisdiccional pleno de la actuación administrativa, pero el legislador puede ordenarla.

Las relaciones entre Ejecutivo y Judicial diseñadas en Derecho Procesal de forma diferenciada se ven afectadas sólo de manera limitada por el artículo 20.2.2 GG precisamente por la ambivalencia del mandato de tutela judicial y la asunción autónoma de tareas por parte del Ejecutivo. Después de todo, el artículo 20.2.2 GG protege la autonomía de ambos Poderes y de las estructuras de toma de decisiones típicas de cada uno de ellos. Esto no suscita objeciones en el caso de una configuración amplia de la legitimación para recurrir (p. ej. § 61 de la Ley Federal de Protección de la Naturaleza -Bundesnaturschutzgesetz, BNatSchG-) ${ }^{162}$, porque el legislador es en principio libre para crear derechos subjetivos y, con ello, para asignar una misión de control típica de los

157 A este respecto, desde la perspectiva de la dogmática de los derechos fundamentales: Jestaedt, Grundrechtsentfaltung (nota 67), págs. 287 ss.; C. Bumke, Der Grundrechtsvorbehalt, 1998, págs. 98 ss.; desde una perspectiva de teoría constitucional, con referencia a la noción kantiana de Derecho: Möllers, Gewaltengliederung (nota 11), págs. 41 y siguiente. Respecto al Derecho Administrativo: R. WAHL, "Die doppelte Abhängigkeit des subjektiven öffentlichen Rechts", DVBl. 1996, pág. 641.

$158 \mathrm{Al}$ respecto supra, IV., 1., c).

159 Lepsius, Parlamentarismus (nota 83), págs. 151 y siguiente.

160 La jurisprudencia del Tribunal Constitucional no es del todo coherente, de una parte BVerfGE 84, 34 ( 48 ss.); 84, 59 (77 ss.), de otra BVerfGE 88, 40 (45, 56 ss.). Soluciona el problema, no obstante, sin recurrir a la organización de poderes.

161 E. SCHMIDT-AßMANN, “Die Kontrolldichte der Verwaltungsgerichte: Verfassungsgerichtliche Vorgaben und Perspektiven", DVBl. 1997, pág. 281 (287 y siguiente).

162 E. GASSNER, Bundesnaturschutzgesetz, 2. ed. 2003, \$ 61, marginales 26 y siguiente; M. H. MüLleR/H. STÖCKEL, Naturschutzrecht, 2. ed. 2003, A1, $\$$ 61, marginales 3 y siguiente; R. SEELIG/B. GÜNDLING, "Die Verbandsklage im Umweltrecht - Aktuelle Entwicklungen und Zukunftsperspektiven im Hinblick auf die Novelle des Bundesnaturschutzgesetzes und supranationale und internationale rechtliche Vorgaben", NVwZ 2002, pág. 1033 (1036 ss.). 
órganos jurisdiccionales. En estos supuestos sólo hay que tener en cuenta que el procedimiento administrativo precedente habrá de adaptarse a la legitimación procesal para que la Administración no se vea confrontada por primera vez en el proceso con asuntos que anteriormente no había tenido oportunidad de tomar en consideración (oportuno p. ej. el §61.3 BNatSchG). Más dudosa, si bien constitucionalmente difícilmente atacable, es la evolución que hace de la tutela judicial frente a la Administración una mera moderadora permanente del Ejecutivo que acompaña al procedimiento administrativo sin valorarlo jurídicamente de forma concluyente ${ }^{163}$. De este modo, el titular individual de derechos se ve confrontado con una motivación estatal permanentemente cambiante para su limitación de libertad cuando, por ejemplo, la aportación tardía de nuevos motivos produce sus efectos también en el procedimiento contencioso-administrativo. Se traspasa el límite del artículo 20.2.2 GG cuando los Tribunales se convierten en socios cooperadores del Ejecutivo que proporcionan a éste sugerencias de motivación para lograr una fundamentación legal de las decisiones que en cualquier caso se han adoptado, lo cual puede aplicarse al Derecho legal sólo con cautela, por ejemplo mediante una interpretación comedida del $₫ 114.2$ de la Ley de la Jurisdicción Contencioso-Administrativa (Verwaltungsgerichtsordnung, $\mathrm{VwGO}^{164}$.

Un elemento esencial del reparto de trabajo entre los Poderes Ejecutivo y Judicial característico de la organización de poderes lo proporciona el transcurso del tiempo. El control jurisdiccional sigue a la decisión ejecutiva. Esto resulta claramente puesto en cuestión cuando existe una tutela cautelar muy desarrollada, sin que las normas legales, en concreto el $\$$ 80.1.1 VwGO, vulneren por ello la organización de poderes ${ }^{165}$. La colisión entre la necesidad de ejecución del segundo Poder, democráticamente legitimada, y la necesidad de control, característica del Estado de Derecho, de un demandante no puede decidirse con carácter general ni en favor del primero ni en favor de este último ${ }^{166}$. En este sentido coincide con el significado temporal de la organización de poderes que aquí se defiende el que la amenazante irreversibilidad de una violación de la libertad individual constituya un criterio decisivo a la hora de conceder la protección judicial cautelar ${ }^{167}$. Por este motivo parece preferible una norma como la del $₫ 123$ VwGO, en el que la suspensión de la decisión administrativa ha de ser justificada en el caso concreto, a una norma tipificadora como la que prevé el $₫ 80$ VwGO.

163 Básicamente sobre este problema: A. TschENTSCHER, «Indiestnahme der Gerichte für die Effizienz der Verwaltung", en: M. Demel y otros (eds.), Funktionen und Kontrolle der Gewalten, 2001, pág. 165 (174 ss.).

164 Sobre el estado de la discusión: M. Gerhard, en: Schoch/SchmidT-Aßmann/Pietzner, $V w G O$ (febrero 2007), \114, marginal 12, a-g.

165 Sobre este problema también: F. SсHOCH, Vorläufiger Rechtsschutz und Risikoverteilung, 1988, págs. 1037 ss.

166 Así era por ejemplo en Derecho inglés antes de su europeización: STJCE, asunto C-213/89, Rec. 1190, I-2433.

$167 \mathrm{Al}$ respecto F. Schoch, en: Schoch/Schmidt-Aßmann/Pietzner, VwGO (febrero 2007), $\S 123$, marginal 10, con referencias adicionales. 


\section{LA ORGANIZACIÓN DE PODERES EN LAS RELACIONES JURÍDICAS VERTICALES}

Los problemas de la organización de poderes en las relaciones jurídicas verticales se plantean por una parte respecto al orden federal (1.), y por otra respecto a las relaciones exteriores (2.).

\section{La ORGANIZACIÓN DE PODERES EN EL EsTADO FEDERAL}

La asunción de una organización "vertical" de poderes a través de la estructura federal de la Ley Fundamental viene siendo reconocida tanto en la jurisprudencia ${ }^{168}$ como en la doctrina ${ }^{169}$ desde hace mucho tiempo. Implica que la estructura federal genera en la organización estatal de la Federación efectos que vienen sustentados por el sistema de la organización de poderes. Esta presunción parece confirmarse a primera vista en la percepción de una multiplicación de los controles característicos del Estado de Derecho y de los procedimientos democráticos de toma de decisiones. Pero esta conexión no supera un examen más preciso.

Con carácter general se reconoce que el artículo 28.1.1 GG obliga también a los Länder a establecer un orden basado en la organización de poderes $^{170}$. Pero entre los niveles de la Federación y de los Länder respectivamente estructurados de acuerdo con la organización de poderes y la organización de poderes de la Federación no existe ninguna relación clara ${ }^{171}$. No toda multiplicación de niveles y órganos soberanos eleva la medida de la organización de poderes, si es que ésta es susceptible de ser elevada. Hay más bien que examinar cómo se refleja el principio federal en la estructura estatal de la Federación para establecer un vínculo normativo concreto entre ambos principios.

La singularidad decisiva de la construcción estatal de la Ley Fundamental la constituye en este sentido la ejecución de las leyes federales por parte de los Länder, artículo 83 GG, y la participación conexa del Bundesrat en la aprobación de las leyes federales, artículo 77 GG. Ambas vienen ordenadas expresamente por la Ley Fundamental y como lex specialis no han de justificarse ante el artículo 20.2.2 GG. En esta estructura no es posible reconocer un

168 Últimamente en BVerfGE 104, 249 (279): "La separación de poderes vertical al servicio también del aseguramiento de la libertad de los ciudadanos..." (voto particular discordante de Di Fabio, Mellinghoff; BVerfG, 2 BvF 6/98, de 15 de julio de 2003, apartado 47.

169 Básico Hesse, Grundzüge (nota 18), marginal 231.

$170 \mathrm{La}$ incorporación de la organización de poderes al mandato de homogeneidad no se deduce del tenor literal, pero no se discute. BVerfGE 2, 307 (319). DreIER, Grundgesetz-Kommentar, vol. II, 2. ed. 2006, Art. 28, marginal 60, con referencias adicionales.

171 C. MÖllers, "Der parlamentarische Bundesstaat", en: J. Aulehner y otros (eds.), Föderalismus, 1998, pág. 81 (97 ss.); ahora en detalle: A. НАмЕвеск, Der demokratische Bundesstaat des Grundgesetzes, 2004, págs. 314 ss. 
reforzamiento de la concepción de la organización de poderes en la Ley Fundamental, sino sólo una excepción permitida por la Constitución ${ }^{172}$. En el caso de las leyes que precisan necesariamente del respaldo del Bundesrat para su aprobación (Zustimmungsgesetze) la Ley Fundamental permite a un gremio compuesto por representantes de los Ejecutivos, cuyos miembros no son democráticamente responsables ante el pueblo de la Federación ni siquiera de manera mediata, participar a través de un proceso no parlamentario y no necesariamente público, artículo 52.3.4 GG, en la legislación de la Federación ${ }^{173}$. La ejecución federalmente cruzada complica además el control parlamentario de la aplicación del Derecho de la Federación ${ }^{174}$ y provoca la formación de una abundancia de gremios intergubernamentales e interadministrativos ${ }^{175}$ que priva materialmente de poder a los Parlamentos de los Länder y les asigna un papel que no difiere mucho del del Bundestag en las relaciones internacionales ${ }^{176}$.

Da igual cómo valore uno el sistema alemán del Federalismo ejecutivo desde la perspectiva político-constitucional: no está en una relación positiva con la organización de poderes de la Ley Fundamental. A diferencia de lo que ocurre en relación con la idea del Estado de Derecho y con la democracia, el principio federal se muestra más bien como perjudicial frente a la organización constitucional de poderes. Esta conexión se ve no sólo oscurecida por la referencia metafórica y jurídicamente imprecisa a una organización "vertical" de poderes, sino que se acaba convirtiendo en lo contrario. Hay que renunciar, por tanto, a ella. Esta interrelación resultará jurídicamente atacable, naturalmente, sólo de manera excepcional, en concreto cuando el Tribunal Constitucional Federal recurra a cuestiones de principio en la interpretación de normas que hagan surgir la necesidad del respaldo obligatorio del Bundesrat para que una ley pueda ser aprobada ${ }^{177}$.

172 En sentido similar respecto al principio democrático para el Bundesrat: JESTAEDT, Demokratieprinzip (nota 6), págs. 286 y siguiente, 289.

173 R. Dolzer, "Das parlamentarische Regierungssystem und der Bundesrat - Entwicklungsstand und Reformbedarf", VVDStRL 58 (1999), pág. 7 (19 ss.); A. RüHRMAIR, Der Bundesrat zwischen Verfassungsauftrag, Politik und Länderinteressen, 2001, págs. 33 ss.; desde una perspectiva histórica y de ciencia política: G. Lenmbruch, Parteienwettbewerb im Bundesstaat, 3. ed. 2000, págs. 77 ss., 158 ss.

174 W.-R. Schenke, "Gesetzgebung zwischen Föderalismus und Parlamentarismus", en: H.-P. Schneider/W. Zeh (ed.), Parlamentsrecht und Parlamentspraxis, 1989, pág. 1485 (1500); U. SCHEUNER, "Verantwortung und Kontrolle in der demokratischen Verfassungsordnung", en: Staatstheorie und Staatsrecht, 1978, pág. 293 (309); T. Groß, Das Kollegialprinzip in der Verwaltungsorganisation, 1999, págs. 186 y siguiente; H.C. RöHL, Der Wissenschaftsrat, 1994, págs. 138 y siguiente; desde una perspectiva de Derecho comparado: D.P. CuRRIE, «Separation of Powers in the Federal Republic of Germany", The American J. o. Comparative Law 41 (1993), pág. 201 (238).

175 E.W. SCHARPF, "Der Bundesrat und die Kooperation auf der dritten Ebene", en: BundesRAT (ed.), Vierzig Jahre Bundesrat, 1989, pág. 121.

176 H. EICHER, Der Machtverlust der Länderparlamente, 1988, págs. 61 ss.

177 BVerfGE 104, 249 (279). Cfr. en la jurisprudencia más antigua el topos del "desplazamiento del sistema federal" (föderale Systemverschiebung) al justificar la necesidad del respaldo favorable del Bundesrat para la aprobación de una ley: BVerfGE 37, 363 (379 y siguiente); 55, 274 


\section{PODER EXTERIOR}

El orden de la Ley Fundamental está orientado en principio, como todo Derecho democrático de organización, hacia la producción interna de Derecho. La organización y legitimación de las relaciones jurídicas exteriores plantea problemas particulares porque el nacimiento de obligaciones de Derecho internacional en contextos intergubernamentales de negociación escapa, por su discurrir temporal, tanto a la configuración parlamentaria como al control judicial. La fijación material de obligaciones surge demasiado pronto.

El artículo 59.2.1 (segunda alternativa) GG asimila expresamente a la reserva general de ley la exigencia del respaldo favorable del Bundestag respecto a las obligaciones exteriores ("materias objeto de competencias legislativas federales $\left.{ }^{178}\right)$, lo cual supone ignorar de manera fundamental y en un doble aspecto la jurisprudencia del Tribunal Constitucional Federal cuando ésta, en primer lugar, concibe la norma del artículo 59.2 GG como límite al derecho de participación del Parlamento y, en segundo lugar, limita este derecho a la modificación formal de Tratados internacionales ${ }^{179}$. Según la doctrina general de la reserva de Parlamento, las reservas de ley positivizadas representan, por el contrario, sólo un nivel mínimo de competencia parlamentaria de decisión. Además, de otros criterios materiales de la Ley Fundamental, como los derechos fundamentales, se derivan obligaciones constitucionales adicionales para la aprobación de normas mediante leyes parlamentarias. Evidentemente el Bundestag puede asumir además más obligaciones de legislar que aquéllas que se le asignan. El Tribunal Constitucional Federal se aparta en el caso del Poder Exterior de esta lógica general de la obligación parlamentaria de legislar y del más amplio poder parlamentario de normación apelando a la organización constitucional de poderes. En este punto halla la doctrina del reparto orgánico adecuado a la función su aplicación práctica más significativa. Pero la referencia a las posibilidades prácticas del Ejecutivo para "reaccionar de manera rápida y adecuada" ${ }^{180}$ no convence apenas como argumento normativo y no aparece tampoco como obligatorio en Derecho comparado. La afirmación, sin embargo, de que la participación del Bundestag no es legislación en sentido funcional ${ }^{181}$ no resulta plausible a la vista del artículo 59.2.1 GG, un argumento por lo demás circular. Los resultados a que se llega con tales fundamentos conducen, ade-

(319 y siguiente); 75, 108 (150). Respecto a la crítica en relación a la cuestión de en qué consiste en realidad el "sistema" que hay que proteger: Lerche, Stil und Methode (nota 12), págs. 354 y siguiente. En contra, por referencia como aquí a la división de poderes: BVerfGE 55, 274 (334), voto particular discordante de ROTTMANN.

178 Esto se dice no sólo en sentido federal, sino que se refiere también de manera indiscutida a la relación entre el Legislativo y el Ejecutivo: BVerfGE 1, 372 (390).

179 BVerfGE 68, 1 (86); 104, 151 (160 ss.). Una crítica de base en R. Wolfrum, "Die Kontrolle der auswärtigen Gewalt", VVDStRL 56 (1997), pág. 38.

180 BVerfGE 68,1 (87).

181 BVerfGE 68, 1 (87) 
más, a contradicciones valorativas evidentes, como el hecho de que el uso pacífico de la energía atómica necesite la aprobación parlamentaria ${ }^{182}$ pero la instalación de armas nucleares en suelo alemán no ${ }^{183}$.

Esto exige reconducir la comprensión del artículo 59.2 GG, como lo hace expresamente su tenor literal, a la doctrina general de la esencialidad (allgemeine Wesentlichkeitslebre). De aquí se deriva que al Bundestag le corresponde según el artículo 59.2 GG un derecho de decisión en aquellas decisiones que satisfagan los estándares generales de la esencialidad. En definitiva, el Bundestag puede reservarse su aprobación también respecto a los desarrollos materiales esenciales de obligaciones de Derecho internacional que se hayan alcanzado mediante decisiones internas de organizaciones internacionales con la presencia de un representante alemán sin que haya habido modificación formal del texto del Tratado en cuestión. De acuerdo con esto, el que el Bundestag le formule al Gobierno mandatos de negociación ${ }^{184}$, ponga en marcha iniciativas para la conclusión de Tratados internacionales $^{185}$, o siga las negociaciones no supone una vulneración del artículo 20.2.2 GG. Los reparos prácticos que con frecuencia se aducen frente a esto pueden quedar debilitados a la luz del Derecho comparado ${ }^{186}$. Sin duda alguna, las posibilidades de participación del Parlamento en las relaciones internacionales siguen siendo también entonces limitadas en la práctica, pero no por ello constitucionalmente menos necesarias. Hay que tomar en consideración, por medio de una nueva comprensión de la participación del Parlamento, la creciente importancia de las relaciones internacionales ${ }^{187}$, lo cual, sin embargo, supone dogmáticamente una equiparación con las doctrinas generales de la reserva de Parlamento. Desde el punto de vista político-constitu-

182 BVerfGE 49, 89 (127).

183 BVerfGE 68, 1 (85 ss.).

184 BVerfGE 1, 351 (369); 1, 372 (395); 77, 170 (232). Cfr. también la alusión en BVerfGE 58, 1 (36). Conforme: M. Dregger, Die antizipierte Zustimmung des Parlaments zum Abschluß völkerrechtlicher Verträge, die sich auf Gegenstände der Bundesgesetzgebung beziehen, 1989, págs. 65 ss.; críticas las reflexiones de Wolfrum, Kontrolle (nota 178), págs. 46 ss., también con referencias a la praxis parlamentaria.

185 BVerfGE 68, 1 (85 y siguiente): "De este modo, el Bundestag no puede en virtud del artículo 59.2.1 GG ni impedir ni obligar al Gobierno a emprender, a no hacerlo o a interrumpir las negociaciones para la conclusión de un Tratado o a diseñar proyectos de Tratado con un determinado contenido, ni puede tampoco obligar a que el Gobierno concluya un Tratado para el que haya emitido una ley de conformidad en los términos del artículo 59.2.1 GG o a que una vez concluido se le ponga fin de acuerdo con el Derecho internacional o se le mantenga". Conforme: BVerfGE 90, 286 (357 y siguiente); crítico como aquí: Wolfrum, Kontrolle (nota 178), págs. 48 y siguiente; G. KRETSCHER, "Gesetzesentwürfe aus der Mitte des Bundestags und völkerrechtliche Verträge", en: Festschrift für Herbert Helmrich, 1994, pág. 537 (537 ss.); U. Fastenrath, Die Kompetenzverteilung im Bereich der Auswärtigen Gewalt, 1986, págs. 239 y siguiente, en cada caso con referencias adicionales.

186 S.A. RiesEnfeld/F.M. Aввотt (eds.): Parliamentary Participation in the Making and Operation of Treaties, 1994, pág. 61; en comparación con los Estados Unidos: Möllers, Gewaltengliederung (nota 11), págs. 366 ss.

187 A.v. Bogdandy, "Parlamentarismus in Europa: eine Verfalls- oder Erfolgsgeschichte?", AöR 130 (2005), pág. 445. 
cional, el artículo 23.3 GG diseña un modelo que a la larga será necesario también para otras obligaciones de Derecho internacional.

El control judicial de las obligaciones internacionales sufre de lege lata bajo la estructura temporal de las obligaciones de Derecho internacional: las pre-obligaciones nacidas en el nivel intergubernamental obstaculizan el control judicial, que no quiere pasar por alto los prevínculos, sin conducir a un conflicto normativo entre Derecho nacional y supranacional. En la práctica esto se puede resolver en cada caso concreto mediante un aplazamiento de la ratificación por parte del Presidente Federal ${ }^{188}$, sin que con ello se subsane el problema estructural de fondo. De lege ferenda habría que pensar, a la vista del dinamizado entramado internacional, en recuperar la competencia del Tribunal Constitucional Federal para la emisión de dictámenes previos, porque entonces el Tribunal estaría autorizado a examinar las obligaciones internacionales en un momento en el que el examen no ha de respetar todavía obligaciones internacionales ${ }^{189}$. Esta competencia no supondría, por su parte, ninguna vulneración de la organización de poderes ${ }^{190}$.

\section{LA ORGANIZACIÓN DE PODERES EN LA SUPREMACÍA DE LA CONSTITUCIÓN}

\section{El Tribunal Constitucional Federal en la organización de poderes}

El Tribunal Constitucional Federal es parte de la organización de poderes, no está por encima de ella. Los artículos 20.2.2 y 92 (segunda frase) GG lo incluyen expresamente en ella como Tribunal ${ }^{191}$. Esta inclusión no puede desvirtuar las funciones del Tribunal Constitucional Federal definidas en otro lugar de la Ley Fundamental, pero pone de manifiesto el hecho, al que con frecuencia se presta poca atención, de que la supremacía de la Constitución se establece en la Ley Fundamental mediante una relación procedimental en la que todo los órganos quedan vinculados a la Ley Fundamental y vigilan, en el marco de sus competencias, que ésta sea respetada. La supremacía de la Constitución no puede tampoco por ello, a la inversa, desvirtuar los límites a

188 Cfr. también el supuesto de hecho en BVerfGE 112, 363.

189 Modelo: Art. 300.6 TCE.

190 Sobre el carácter jurisdiccional del dictamen, supra, IV., 1., b).

191 Esto se destaca con demasiada poca frecuencia. Véase sin embargo: G. Roellecke, "Aufgaben und Stellung des Bundesverfassungsgerichts im Verfassungsgefüge", en: J. IsENSEE/P. KirCHHOF (eds.): Handbuch des Staatsrechts, vol. II, 1987, \&53, marginal 1, págs. 34 y siguiente; A. Voßrunle, en: v. Mangoldt/Klein/StarcK, Grundgesetz-Kommentar, vol. III, 5. ed. 2005, Art. 93, marginales 19 y siguiente; K. SCHLAich, "Das Bundesverfassungsgericht im Gefüge der Staatsfunktionen", VVDStRL 39 (1981), pág. 99 (106 ss.); en conexión con éste: K. SCHLAICH/S.KORIOTH, Bundesverfassungsgericht, 7. ed. 2007, págs. 279 ss.; C. STARCK, "Das Bundesverfassungsgericht in der Verfassungsordnung und im politischen Prozeß", en: Festschrift BVerfG, 2001, pág. 1 (3 ss.). 
la actuación judicial que se le señalan al Tribunal Constitucional ${ }^{192}$. El problema fundamental de la legitimidad de los Tribunales Constitucionales, que en un procedimiento exclusivo y limitado a las partes en el proceso, anulan decisiones democráticas del legislador ${ }^{193}$, no puede de este modo solucionarse dentro de la Ley Fundamental: de constitutione lata el Derecho alemán ha optado por una jurisdicción constitucional fuerte que no responde sin fisuras al ideal teórico-constitucional del autogobierno democrático ${ }^{194}$.

Como norma de procedimiento y organización, la organización de poderes le señala a la jurisdicción constitucional ante todo límites sólo procedimentales y organizativos. Para la interpretación de los preceptos materiales de la Ley Fundamental esto tiene dos tipos de repercusiones mediatas, de una significación jurídica diferente:

$\mathrm{Si}$, en primer lugar, la organización de poderes no afecta a cuestiones jurídicas materiales, no puede tampoco concebirse cualquier interpretación del Derecho material, por absurda que sea, como una vulneración de la organización de poderes. La opinión, defendida en la jurisprudencia y en la doctrina ${ }^{195}$, según la cual un Tribunal que desarrolle el Derecho de manera extremadamente amplia actuaría como legislador y vulneraría con ello la organización de poderes no se sostiene. También en este supuesto actúa el Tribunal en un procedimiento judicial, por iniciativa ajena, en un caso concreto. Precisamente no deja de actuar como Tribunal en relación a la organización y al procedimiento, los criterios relevantes para la organización de poderes. La vulneración del Derecho material no puede extenderse a los criterios de la organización de poderes. Por este motivo el Tribunal Constitucional Federal no está autorizado para anular, como violaciones del artículo 20.2.2 GG, decisiones de los Tribunales especializados. Esto aparecería más bien como una inadecuada extensión de su competencia de control al Derecho infraconstitucional.

En segundo lugar, si el Tribunal Constitucional Federal opera ampliamente con dimensiones iusfundamentales objetivas y en ese proceso hace surgir de los mandatos iusfundamentales de protección obligaciones de actuación

192 En este punto se halla el núcleo de la preocupación por imponer a la jurisdicción constitucional límites jurídico-funcionales. Básico: H. EHмKE, "Prinzipien der Verfassungsinterpretation", VVDStRL 20 (1963), pág. 53 (73); G.F. SCHUPPERT, Die verfassungsgerichtliche Kontrolle der auswärtigen Gewalt, 1973, págs. 162 ss.; K. Hesse, "Funktionelle Grenzen der Verfassungsgerichtsbarkeit" (1981), en: Ausgewäblte Schriften, 1984, pág. 311; un análisis crítico de la jurisprudencia en: W. Heun, Funktionell-rechtliche Schranken der Verfassungsgerichtsbarkeit, 1991.

$193 \mathrm{Al}$ respecto, breve: M. Troper, "The Logic of Justification of Judicial Review", International Constitutional Law, 1 (2003), pág. 99 (109 ss.).

194 Reproduce la importante discusión americana: U.R. HALTERN, "Verfassungsgerichtsbarkeit, Demokratie und Mißtrauen, 1998, págs. 169 ss.; J. RiECKEn, Verfassungsgerichtsbarkeit in der Demokratie, 2003, págs. 390 ss.

195 En este sentido BVerfGE 9, 89 (101); 34, 269 (285 y siguiente); 96, 375 (394); NJW 2002, 3635 (3636). En sentido similar BVerfGE 31, 145 (173). Sobre la jurisprudencia en su conjunto: B. PIEROTH/T. Aubel, "Die Rechtsprechung des Bundesverfassungsgerichts zu den Grenzen richterlicher Rechtsfortbildung", JZ 2003, pág. 504 (505 ss.). 
para el legislador, le da la vuelta al orden cronológico de actuación previsto por la organización de poderes y se convierte en un órgano de iniciativa política democráticamente no responsable ${ }^{196}$. Esto a su vez no puede entenderse como una vulneración del artículo 20.2.2 GG, pero a nivel de teoría constitucional plantea un considerable problema de legitimidad del Tribunal, que se politiza a sí mismo.

Para el Derecho procesal se derivan consecuencias jurídicas más claras. La Ley Fundamental exige en los artículos 20.2.2 y 92 (segunda frase) GG una compensación legal entre la inclusión del Tribunal en la organización de poderes acorde con la Constitución y su misión como intérprete del ordenamiento constitucional. El Tribunal Constitucional Federal no es, por ello, de ninguna manera dueño de su procedimiento ${ }^{197}$, sino que está vinculado al Derecho procesal de rango legal siempre que éste no vulnere las normas pertinentes del Título IX de la Ley Fundamental. El Tribunal puede salirse rápidamente del marco del artículo 20.2.2 GG si se aparta del Derecho procesal de rango legal. Como Tribunal que sólo puede actuar por iniciativa ajena tampoco se le permite al Tribunal Constitucional Federal dictar sentencia una vez que se haya retirado un recurso de amparo ${ }^{198}$, dictar resoluciones con carácter de urgencia sin la correspondiente solicitud ${ }^{199}$ o rechazar solicitudes como manifiestamente infundadas sin examen de admisibilidad aludiendo a la situación jurídica material ${ }^{200}$. En todas estas prácticas el Tribunal se transformaría en una instancia constitucional de valoración que se habría liberado de las exigencias de un procedimiento judicial, pero con ello se habría desvinculado también de la organización de poderes de la Ley Fundamental y la habría vulnerado. Los mismos reparos se les pueden formular a los fallos de las sentencias del Tribunal que van más allá de una mera declaración de in-

196 Sobre esta interrelación: K. Hesse, "Die verfassungsgerichtliche Kontrolle der Wahrnehmung grundrechtlicher Schutzpflichten", en: Festschrift für Ernst Gottfried Mabrenbolz, 1994, pág. 541 (553 y siguiente); G. Hermes, "Verfassungsrecht und einfaches Recht - Verfassungsgerichtsbarkeit und Fachgerichtsbarkeit", VVDStRL 61 (2002), págs. 119 ss. (127 y siguiente); Heun, Schranken (nota 192), págs. 66 ss.

197 Cfr. ya BVerfGE 1, 109 (110 y siguiente). J. Wieland, "Der Herr des Verfahrens", en: Festschrift für Ernst-Gottfried Mabrenbolz, 1994, pág. 885, con referencias adicionales; sobre la idea dogmática relacionada de la "autonomía" del Derecho procesal constitucional: P. HÄBERLE, "Die Eigenständigkeit des Verfassungsprozeßrechts", JZ 1973, pág. 451; una crítica justificada, destacando el papel del legislador, en Sснагсн/Korioth, Bundesverfassungsgerichts (nota 191), págs. 136 ss.; E. KleIn, "Verfassungsprozeßrecht”, AöR 108 (1983), pág. 561 (618 ss.); del mismo autor, "Verfahrensgestaltung durch Gesetz und Richterspruch", en: Festschrift BVerfG, 2001, pág. 507 (510 ss.).

198 Así BVerfGE 85, 109 (114); 98, 218 (242 y siguiente). En contra: H. Bauer/C. Möllers, "Die Rechtschreibreform vor dem Bundesverfassungsgericht", JZ 1999, 697 (697 y siguiente); Voßkuhle, en: v. Mangoldt/Klein/Starck (nota 191), Art. 93, marginal 21.

199 Cfr. también sobre la existencia de medidas cautelares con independencia de la sentencia sobre la cuestión de fondo: BVerfGE 81, 53 (57); 82, 353. Referencias y críticas en: E. SсHосн, "Einstweilige Anordnung", en: Festschrift BVerfG, 2001, 695 (699).

200 BVerfGE 53, 100 (106); 79, 223 (231); 96, 1 (5). Sobre la crítica: VoßKuhle, en: v. ManGOLDT/KLEIN/STARCK (nota 191), Art. 93, marginal 21. 
constitucionalidad ${ }^{201}$ en la medida en que se mantienen sin fundamento en la Ley del Tribunal Constitucional Federal (Bundesverfassungsgerichtsgesetz, BVerfGG $)^{202}$. Cuando el Tribunal anuncia, fijando un plazo para ello ${ }^{203}$, la entrada en vigor de normas del propio Tribunal Constitucional sin duda ha abandonado este marco. También las sentencias apelativas (Appellentscheidungen) resultan en esta medida cuestionables ${ }^{204}$. Dado que no hay disponible ninguna instancia que controle al propio Tribunal Constitucional es una tarea importante y todavía infravalorada de la doctrina del Derecho del Estado la de recordar la naturaleza jurisdiccional del Tribunal Constitucional y su vinculación al Derecho procesal parlamentariamente legitimado.

La intensidad del control del Tribunal Constitucional Federal no se sujeta a ningún límite abstracto teórico-constitucional ${ }^{205}$, sino que sigue los criterios establecidos por la Ley Fundamenta2 ${ }^{206}$. En relación a la organización de poderes esto significa que en todo caso se puede deducir de las normas constitucionales pertinentes una intensidad limitada del control que lleva a cabo el Tribunal Constitucional. Lo mismo que la argumentación sobre la intensidad del control que practica el Tribunal Constitucional ${ }^{207}$, también un procedimiento constitucional propio puede configurarse de tal manera que ya no resulte comprensible en todos sus elementos en el marco del proceso ante el Tribunal Constitucional. Un ejemplo importante de esto lo representa el artículo 68.1.1 GG. La cuestión relativa a la relación política de confianza entre el Canciller Federal y la mayoría parlamentaria no es como tal apenas susceptible de indagación judicial. Esto lo confirma la dificultosa puesta al día del discurrir político sin significación normativa palpable en la primera sentencia sobre la disolución del Bundestag ${ }^{208}$. La apreciación de la estabilidad política es, en su mezcla de pronóstico fáctico y valoración política, todavía más inaccesible para los Tribunales que los requisitos empíricos de las decisiones legales, es decir, que el supuesto indiscutido de la prerrogativa legislativa de estima-

201 La sorprendente pretensión conformadora del Tribunal se manifiesta también en Derecho comparado: W. Heun, "Rechtliche Wirkungen verfassungsgerichtlicher Entscheidungen", en: C. STARCK (ed.), Fortschritte der Verfassungsgerichtsbarkeit in der Welt II, 2006, pág. 173.

202 Cfr. la interpretación provisional, procesalmente poco observada, de la ley G-10 en BVerfGE 93, 181 (197 ss.). Además BVerfGE 88, 203 (335); al respecto el análisis justificativo: P. LERCHE, "Das Bundesverfassungsgericht als Notgesetzgeber", en: Festschrift für Günter Gitter, 1995, pág. 509; una crítica fundamental a la deducción de la facultad de ejecución a partir de las competencias materiales de control en W. ROTH, "Grundlage und Grenzen von Übergangsanordnungen des Bundesverfassungsgerichts zur Bewältigung möglicher Folgeprobleme seiner Entscheidung", AöR 124 (1999), pág. 470 (489 y siguiente).

203 Cfr. por ejemplo: BVerfGE 33, 303 (305); 72, 330 (333); 100, 104 (106).

204 Entre otras muchas: BVerfGE 16, 130 (141 ss.); 101, 158 (159 y siguiente); crítico: E. BENDA/E.KLeIn, Verfassungsprozeßrecht, 2. ed. 2001, marginales 1279 y siguiente.

205 Respecto a la crítica a la doctrina de los criterios jurídico-funcionales de la jurisdicción constitucional pero que no considera en qué medida éstos podrían deducirse de la organización de poderes: Jestaedt, Grundrechtsentfaltung (nota 67), págs. 173 ss.

206 SCHLAich/KoRIOTH, Bundesverfassungsgericht (nota 191), marginal 537.

207 Supra, IV., 2., b).

208 BVerfGE 62, 1 (51 ss.). 
ción ${ }^{209}$. Como presunción acerca de relaciones políticas presentes y futuras entre órganos constitucionales democráticamente responsables, una noción material de la confianza política no responde a la lógica del examen judicial. Sobre todo, sin embargo, el procedimiento de la Ley Fundamental involucra a tres órganos constitucionales que han de juzgar todos ellos la cuestión de si subyace el supuesto de hecho del artículo 68.1.1 GG. De todos modos, en caso de un consenso entre los tres órganos no es posible identificar qué circunstancias podrían justificar una apreciación discordante del Tribunal. Como plasmación jurídica de un proceso de formación de la voluntad democrática configurado de manera abierta, tal apreciación no se correspondería con la estructura de organización de poderes de la Ley Fundamental. El Tribunal debería limitarse a un mero control procedimental ${ }^{210}$.

\section{LÍMITES A LA REFORMA: EL ARTícUlO 79.3 GG}

La organización de poderes de la Ley Fundamental forma parte de los principios protegidos por el artículo $79.3 \mathrm{GG}^{211}$. Para determinar el contenido nuclear de la organización de poderes hay por su parte que retornar a su raíces democráticas y a las derivadas del Estado de Derecho. El artículo 79.3 GG garantiza desde esta perspectiva la realización institucional equitativa tanto de la autodeterminación democrática como de la persecución individual de la libertad. Esto implica la garantía de los procedimientos representativos de la autolegislación democrática y su efecto jurídico vinculante así como la garantía de un examen jurídico, políticamente independiente, de las injerencias en las esferas individuales de libertad. Las amenazas prácticas proceden en esta medida sólo de reformas constitucionales que limiten normativa o fácticamente el examen judicial de la actuación estatal, como en el caso de reformas constitucionales de los artículos 10.2.2 y 13.3 a 6 GG. En este punto los límites del artículo 79.3 GG se alcanzan en cualquier caso relativamente pronto, porque la organización de poderes pone en manos sólo de procedimientos jurisdiccionales una decisión definitiva acerca del alcance de los derechos subjetivos en el caso concreto. En el caso de las injerencias en derechos fundamentales, la organización estatal no puede dejar que las mismas se resuelvan

209 BVerfGE 50, 290 (332 y siguiente); 65, 1 (55); 73, 40 (91 y siguiente); 88, 87 (97); 95, 267 (314); 100, 271 (286); 105, 61 (72); 108, 232 (311).

210 Acertadamente: BVerfGE 114, 121 (182 ss.) (voto particular discordante de LüBBEWolfF). Asimismo consecuente contra una materialización del artículo 68 GG: T. HERBST, "Die auflösungsgerichtete Vertrauensfrage", Der Staat 45 (2006), pág. 45 (61 ss., 65 ss.). Similar en definitiva: F. REIMER, "Vertrauensfrage und Bundestagsauflösung bei politischer Anscheinsgefahr", JuS 2005, pág. 680 (681); en sentido diferente, pero sin considerar el reparto institucional de trabajo exigido por la organización de poderes: C. STARCK, "Anmerkung", JZ 2006, pág. 1053 (1055 y siguiente).

211 H. Dreier, en: Dreier, Grundgesetz-Kommentar, vol. II, 2. ed. 2006, Art. 79 III, marginal 50; en sentido similar Sommermann, en: v. Mangoldt/Kiein/STARCK (nota 13), Art. 20, marginal 205. 
entre el Legislativo y el Ejecutivo (con exclusión, pues, del Poder Judicial) sin salirse del marco de la tríada del poder estatal. La Ley Fundamental no conoce, por el contrario, ninguna justificación para la exclusión de determinadas injerencias de la tutela de los jueces y una transferencia al control de gremios parlamentarios. Las necesidades de regulación, por ejemplo en relación a las cuestiones de la seguridad pública o de la protección de secretos, han de resolverse en el marco del procedimiento judicial ${ }^{212}$. En este medida, un contenido fundamental de la garantía de la tutela judicial del artículo 19.4 GG queda también comprendido por el artículo 79.3 GG por la vía de la organización de poderes ${ }^{213}$.

\section{SOBRE EL MÉTODO DE INTERPRETACIÓN DEL ARTÍCULO 20.2.2 GG}

La interpretación de la organización de poderes en el artículo 20.2.2 GG plantea especiales problemas que han de ser brevemente abordados para finalizar. La organización de poderes regula potencialmente el conjunto de la actuación estatal, es manifestación de dos decisiones básicas de la Ley Fundamental en favor de la democracia y de la protección de la libertad individual, característica del Estado de Derecho, y encuentra después de todo en muchos casos su expresión en primer lugar en disposiciones concretas del Derecho de organización de la Ley Fundamental ${ }^{214}$. Esta inusual combinación de carácter principial, de una parte, y la remisión a normas técnicas concretas, de otra, puede haber sido una causa esencial de que la organización de poderes bajo la Ley Fundamental haya hallado tan escaso interés científico. El esfuerzo dogmático y metodológico que exigía una norma tan básica parecía desproporcionado cuando las normas pertinentes podían de todos modos solucionar un problema de manera fiable. Que esta conclusión no era obligatoria se puso de manifiesto ya en la praxis del Tribunal Constitucional que se vio una y otra vez en la necesidad de buscar orientaciones normativas fundamentales tras un precepto relevante.

Por esta razón una comprensión inductiva del artículo 20.2.2 GG que pretendía deducir el significado de la norma de preceptos especiales de la Ley Fundamental condujo a errores. Naturalmente uno no va a resolver de nuevo supuestos de hecho claramente regulados en la Ley Fundamental por referencia a la organización de poderes, aquí se aplica el principio de la primacía de la lex specialis. Con ello, sin embargo, desaparece también la necesidad de desarrollar un contexto normativo supraordenado. No obstante, en los su-

$212 \mathrm{Al}$ respecto las indicaciones en BVerfGE 101, 106 (129).

213 En sentido diferente, sin embargo: BVerfGE 30, 1 (27 y siguiente); en contra ya: G. DüRIG, "Zur Bedeutung und Tragweite des Art. 79 Abs. III des Grundgesetzes (ein Plädoyer)", en: Festschrift für Theodor Maunz, 1971, pág. 41 (48 ss.). Asimismo en sentido diferente, si bien en un caso menos drástico desde el punto de vista de la técnica de protección jurídica: BVerfGE 109, 279. 214 Supra, III. 
puestos en los que no existe tal claridad, en los cuales, pues, la norma relevante no tiene preparada una solución, no se puede deducir de ella tampoco nada para la organización de poderes. Si la organización de poderes se agotase en las disposiciones individuales de naturaleza jurídico-organizativa de la Ley Fundamental, podría perfectamente renunciarse a ella.

Una concreción del artículo 20.2.2 GG que procede, como aquí, de forma deductiva tiene ante todo que justificar su deducción de la Ley Fundamental para orientar entonces la interpretación de normas más concretas. En ese proceso la organización de poderes no funciona de ninguna manera como un principio en el sentido de la doctrina de los principios $^{215}$, aunque sólo sea porque en el contexto de naturaleza jurídico-organizativa y procedimental no hay nada que optimizar. Al aplicar el artículo 20.2.2 GG habrá más bien que definir la ubicación del problema en la relación orgánica de reparto de trabajo de la Ley Fundamental. Esta apreciación no puede sin más apartar las otras normas relevantes, pero sí que puede orientar la determinación de su significado. Aplicado a tres ejemplos que ya se abordaron anteriormente: de una comprensión sistemática de la organización de poderes se pueden deducir razones en contra de la admisión de elementos adicionales, justiciables y no escritos, del supuesto de hecho del artículo 68.1.1 GG que plasmen jurídicamente la formación informal de la voluntad entre Bundestag, Canciller Federal y Presidente Federal más allá de las normas de procedimiento ${ }^{216}$. Tal comprensión suministra puntos de referencia contra el desarrollo de criterios especiales para el artículo 59.1.2. GG que se apartan de las normas generales de la reserva de $\operatorname{le}^{217}$. Ofrece finalmente una distinción entre la generalidad de la garantía de la tutela judicial en el artículo 19.4 GG y la generalidad de un examen completo del contenido de las decisiones administrativas por parte de los Tribunales.

Los ejemplos ilustran el carácter abierto y la necesidad de orientación de las normas relevantes, pero sobre todo documentan la posibilidad de mantener, y no de desvirtuar, el contenido normativo de la norma al recurrir a la organización de poderes. Finalmente muestran que también la referencia a un planteamiento tan fundamental como el de la organización de poderes puede aportar argumentos para interpretar de manera reservada, es decir, sin admitir presunciones no escritas, una norma de la Ley Fundamental. La orientación sistemática y la fidelidad al texto no tienen por qué entrar en contradicción.

\section{CONCLUSIÓN}

Sólo en escasos supuestos pueden derivarse incisivas consecuencias jurídicas y claros veredictos de inconstitucionalidad del principio de la organiza- 
ción de poderes del artículo 20.2.2 GG. La comprensión teórico-organizativa de que la simplicidad, precisión y generalidad se logran las unas a costa de las otras, pasa factura también en relación a esta norma ${ }^{218}$ : el artículo 20.2.2 GG ofrece un contenido normativo más bien general y no tanto simple o selectivo. En la mayoría de los casos, el contenido de la norma se enlaza en su contexto de significado con otros preceptos especiales de la Ley Fundamental. Esto no supone, sin embargo, que, como se asume muchas veces, la norma no tenga contenido normativo propio alguno, ni que se excluya aportar una determinación dogmática precisa de los tres Poderes estatales previstos por la Ley Fundamental.

En la mediación jurídico-organizativa y procedimental de autodeterminación democrática y protección de la libertad individual característica del Estado de Derecho el artículo 20.2.2 GG desarrolla un contenido más preciso que le permite determinar constitucionalmente tanto los tres Poderes como las relaciones jurídicas entre ellos. En ese proceso es importante ver que la organización de poderes no es sólo un planteamiento que limita las posibilidades conformadoras del legislador del procedimiento y la organización, sino que la organización de poderes protege también el carácter abierto del proceso democrático de formación de la voluntad y del procedimiento legislativo, y demanda en no pocos supuestos, por ejemplo para el Derecho procesal constitucional, una normativa legal detallada. A la vez, el desarrollo sistemático del artículo 20.2.2 GG apoya también la concreción de normas constitucionales específicas.

TITLE: Dogmatic of the organization of powers in the Constitution of Germany.

ABSTRACT: Despite its great practical importance for the jurisprudence of the German Federal Constitutional Court there has been not too much academic interest in the doctrinal structure of the principle of separated powers in Art. 20 (2) (2) Basic Law since 1949. Many contributions claimed that the principle had no normative value in itself, only being the sum of the more specific norms in the constitution. But even a first look at the case material shows that the German Federal Constitutional Court makes a regular and wide use of the principle. This fact as well as the challenging theoretical problems of the idea of separated powers make it necessary to think over a systematic frame for this constitutional principle. After an analysis of central propositions of the court and the literary discussion the contribution tries to develop a new account for a systematic doctrine of the concept of "separated powers" that stresses the fact that Art. 20 (2) (2) Basic Law distinguishes between three powers without necessarily separating them: this is the reason to name the underlying principle "Gewaltengliederung", $i . e$. "arrangement" of powers. The central assumption of this approach is that the main function of a three-parted government is the dissolution of the conflict between democratic collective self-determination and the protection of individual freedom by rule of law 
standards. Democracy and Rechtsstaat are codified in Art. 20 Basic Law. Both enjoy the same normative value, and both stay in a potential conflict with each other. Instead of solving this conflict by any substantial priority rule the constitution dissolves it by a governmental division of labour in which the law-production of the three branches develops from the open, politicized, future-oriented and general form of legislative decisionmaking to the legally determined, pastoriented and highly individualized decision-making procedures of the judicial branch. Between these two poles acts the executive branch as a mediating structure. This reconstruction is integrated into the doctrine of the Basic Law and used to give a substantial legal definition of the three branches of government, the rules that govern the legal relationships between them, the meaning of federalism for the concept of a three-parted government, and the role of the constitutional court within this system.

RESUMEN: A pesar de su gran importancia práctica para la jurisprudencia del Tribunal Constitucional Federal alemán, no ha habido desde 1949 demasiado interés académico en la estructura dogmática del principio de separación de poderes del artículo 20.2.2 GG. Muchos trabajos alegaban que el principio no tenía valor normativo en sí mismo, sino que era sólo la suma de normas constitucionales más específicas. Pero incluso un primer vistazo al material casuistico muestra que el Tribunal Constitucional Federal alemán hace un uso regular y amplio del principio. Este hecho y los desafiantes problemas teóricos de la idea de la separación de poderes hacen necesario plantearse un marco sistemático para este principio constitucional. Después de un análisis de las propuestas del Tribunal y de la discusión doctrinal, el trabajo intenta desarrollar una nueva explicación para una teoría sistemática del concepto de la "separación de poderes" que subraye el becho de que el articulo 20.2.2 GG diferencia entre los tres Poderes sin separarlos necesariamente. Éste es el motivo para denominar el principio subyacente "Gewaltengliederung", es decir "organización" de poderes. La suposición central de esta aproximación es que la función principal del gobierno tripartito es la solución del conflicto entre autodeterminación democrática colectiva y la protección de la libertad individual a través de los estándares del Estado de Derecho. Democracia y Estado de Derecho están codificados en el artículo 20 GG. Ambos gozan del mismo valor normativo, y ambos se hallan en un conflicto potencial entre si. En vez de resolver este conflicto mediante una regla material de prioridad, la Constitución lo resuelve a través de una división gubernamental del trabajo en la que la producción jurídica de las tres ramas va desde la decisión legislativa abierta, politizada, prospectiva y en forma general, a los procedimientos de toma de decisiones legalmente determinados, retrospectivos y altamente individualizados de la jurisdicción. Entre estos dos polos el Ejecutivo opera como una estructura de mediación. Esta reconstrucción se integra en la dogmática de la Ley Fundamental y se emplea para dar una definición legal material de las tres ramas de gobierno, las reglas que presiden las relaciones legales entre ellos, el significado del federalismo para la concepción de un gobierno tripartito, y el papel del Tribunal Constitucional dentro de este sistema.

KeY WORDS: "Arrangement" of powers. Principle of separated powers. Art. 20 (2) Basic Law. Rule of law. Democracy. Self-determination. Individual freedom.

Palabras Clave: Organización de poderes. Principio de separación de poderes. Artículo 20.2 de la Ley Fundamental. Estado de Derecho. Democracia. Autodeterminación. Libertad individual. 